
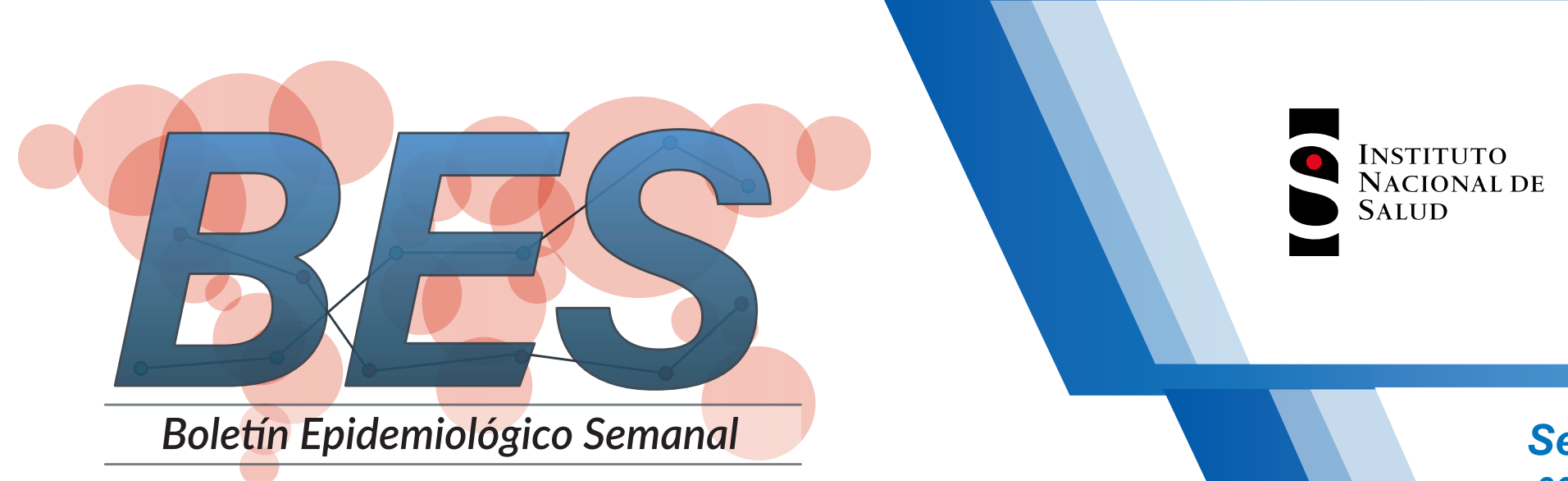

\section{Colombia, 2020}

Enfermedades

transmitidas por alimentos

\section{1 Brotes}

\section{0 casos involucrados}

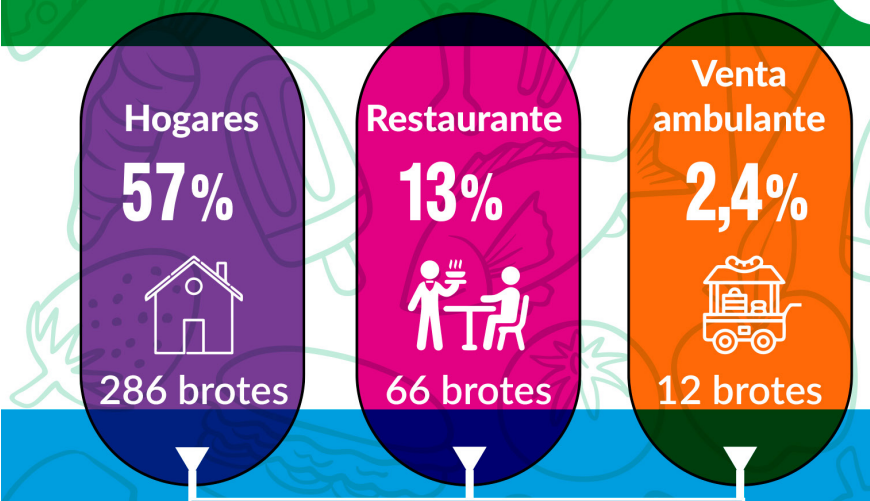

Lugares con mayor proporción
Grupos de edad mas afectados

20-49 años

10-19 años 50-74 años

La inocuidad de los alimento es un asunto de todo

\section{Durante la preparación de alimentos...}

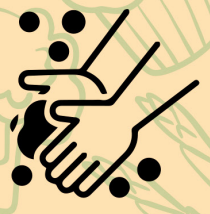

Recordemos el lavado de manos antes, durante y al cambiar do actividad
Siempre lavemos y desinfectemos frutas y verduras

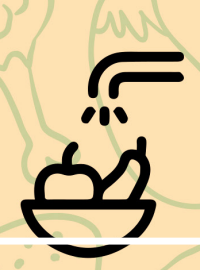

Mantengamos limpia y ordenada la nevera, es donde almacenamos los productos perecederos en el hogar

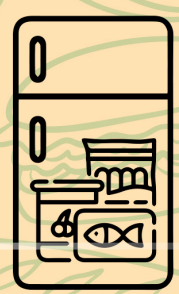

Evitemos el contacto entre alimentos ciuiúus y cocidos

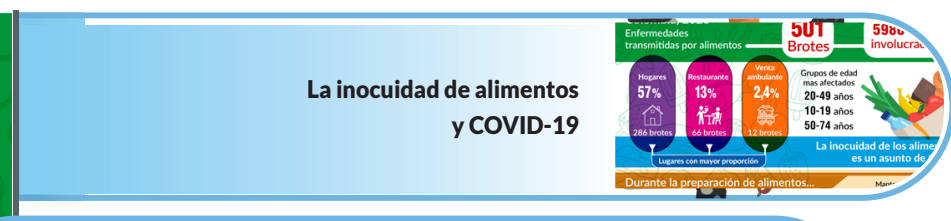

Situación nacional Los eventos en salud pública con mayor frecuencia y el cumplimiento de la notificación de las entidades territoriales.

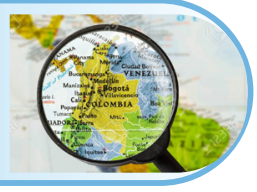

Mortalidad Número de casos notificados al Sivigila, por eventos de interés en salud pública

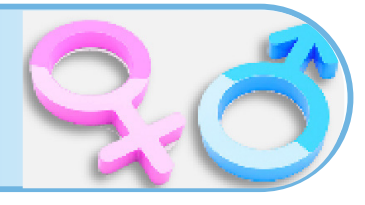

Eventos trazadores Vigilancia en el comportamiento rutinario, siendo un indicador de brotes o emergencias en salud pública.

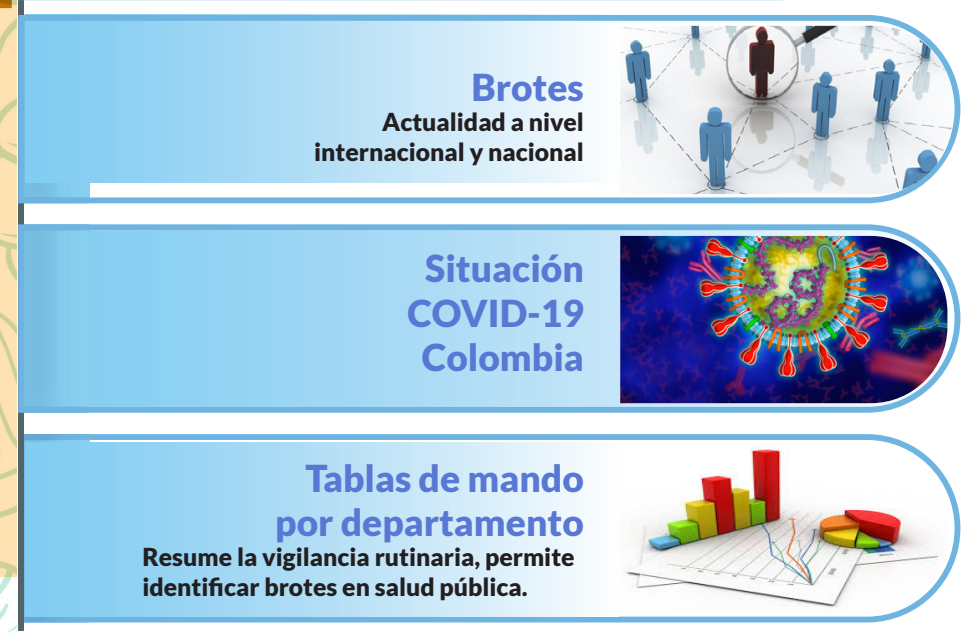




\section{La inocuidad de alimentos y COVID-19:}

\section{¿Se puede contraer la COVID 19 por el consumo de alimentos?}

La evidencia indica que los coronavirus necesitan un huésped vivo animal o humano para multiplicarse, por lo cual no pueden hacerlo en los alimentos. Actualmente no hay ningún caso confirmado de COVID-19 transmitido a través de alimentos o envases de alimentos. La transmisión de virus a través de los alimentos requiere que una persona consuma suficientes virus infecciosos para provocar una infección. Actualmente no hay suficientes datos para decir cuánto SARS-CoV-2 se requiere para provocar una infección. Además, la contaminación de alimentos y envases de alimentos ha sido, hasta la fecha, un evento extremadamente raro. La evidencia actual no respalda los alimentos o el envasado de alimentos como una ruta de transmisión del SARS-CoV-2 a los humanos.

\section{¿Puede el virus vivir en la superficie de los envases de alimentos?}

Como se mencionó, los coronavirus necesitan un huésped vivo para multiplicarse y sobrevivir, esto no pueden hacerlo en la superficie de los envases de los alimentos. En condiciones experimentales, el virus puede sobrevivir en una variedad de superficies, como el plástico o el cartón que se utilizan en los envases, pero es poco probable que este tipo de exposición sea suficiente para enfermar a una persona. Por lo anterior, no se considera necesaria la desinfección de los materiales de los envases de los alimentos, sino el lavado de manos adecuado antes y después de manipular los envases de alimentos.

\section{¿Puede el virus transmitirse por el consumo de alimentos cocinados, in- cluyendo productos de origen animal?}

El coronavirus que causa la COVID-19 no puede transmitirse por el consumo de alimentos cocinados ya que puede eliminarse a la temperatura de cocción de los alimentos. Recordemos que las carnes deben cocinarse a una temperatura mínima de $70^{\circ} \mathrm{C}$ para eliminar los microorganismos y que esta práctica es una de las 5 claves de la inocuidad de los alimentos.

\section{¿Es seguro ir a las tiendas y mercados de alimentos?}

En cuanto a si es seguro ir a las tiendas y mercados de alimentos, la respuesta es sí, ya que no hay evidencia de riesgo por la presencia de alimentos.

Es importante seguir las medidas implementadas en el mercado o supermercado y mantener la distancia física de otras personas al seleccionar los alimentos y en la fila, así como mantener las manos limpias y evitar salir a comprar si se tiene algún síntoma.

\section{¿Es segura la compra de alimentos a domicilio?}

La compra de alimentos será segura si el proveedor sigue buenas prácticas de higiene personal y si se mantiene la temperatura adecuada de los alimentos, ya sean calientes o en cadena de frío. Recordemos que la inocuidad de los alimentos debe procurarse a lo largo de toda la cadena alimentaria incluyendo el transporte y distribución. De acuerdo con lo que se ha mencionado, se recomienda el lavado de manos adecuado después de recibir el domicilio.

\section{¿Cómo deben exponerse los productos de panadería y confitería?}

Con relación a la exposición de los productos de panadería y confitería en establecimientos comerciales, se aconseja tener en cuenta las buenas prácticas de higiene en la manipulación de los alimentos cuando se está cerca de los estantes con alimentos sin envolver, lavar y desinfectar con frecuencia los mostradores y utensilios, y considerar envolver los alimentos o aislarlos mediante vitrinas.

\section{¿Podemos los humanos transmitir el virus a los animales de consumo o viceversa?}

Hasta ahora no hay evidencia de que los animales de consumo pueden transmitirnos el virus ni a la inversa, los resultados de los estudios realizados al respecto han mostrado que los animales de consumo como aves de corral, bovinos y porcinos, entre otros, no son susceptibles a la infección. 


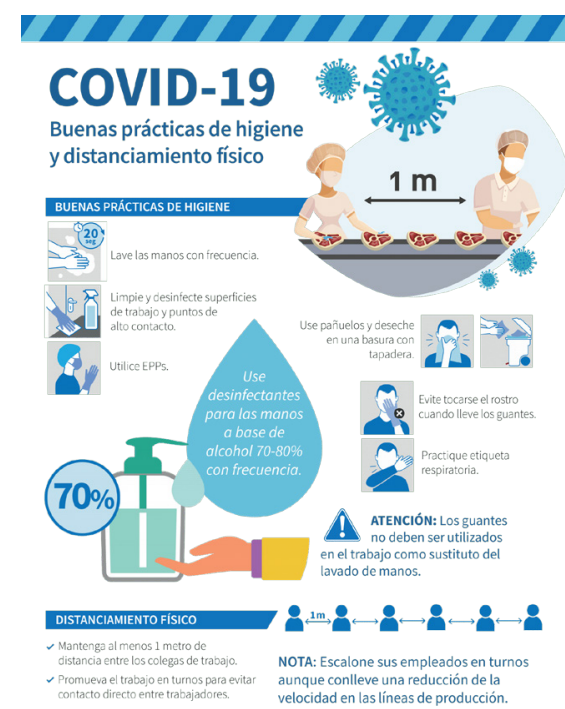

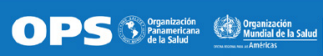

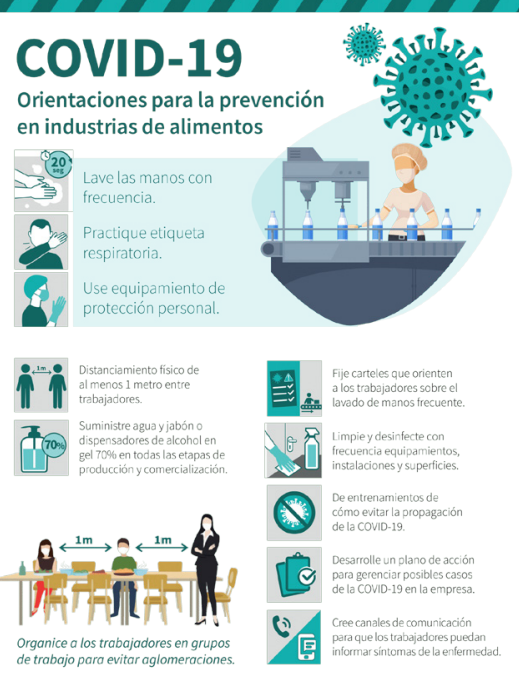

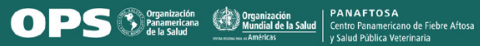

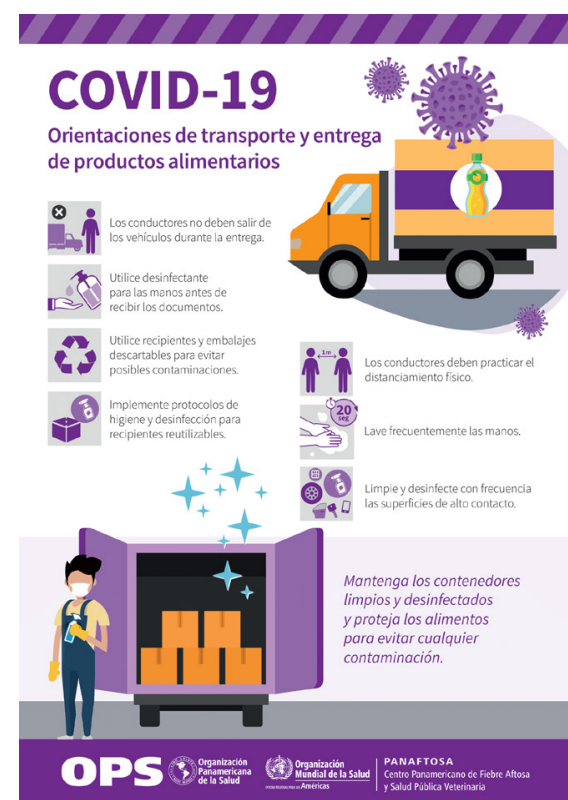

Q

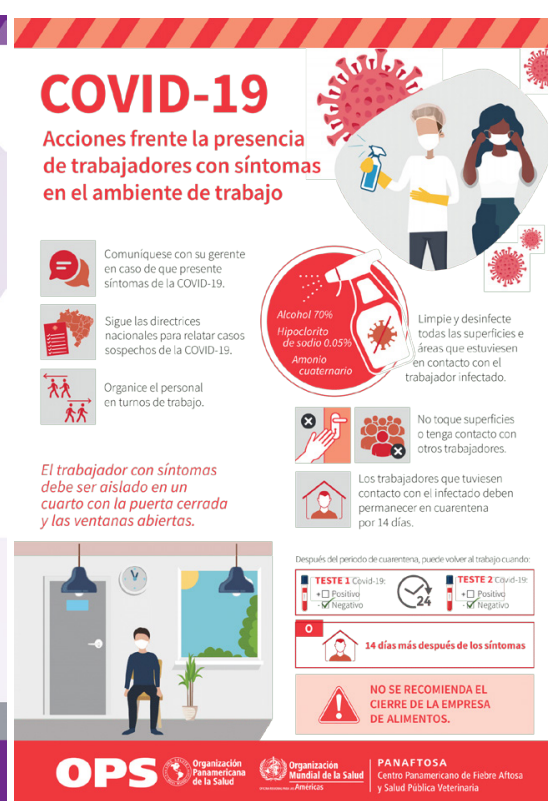

La OMS, la OPS y el Centro Panamericano de Fiebre Aftosa y Salud Pública Veterinaria de la OMS, ha puesto a disposición algunos materiales infográficos en el marco de la celebración del día mundial de la inocuidad de los alimentos con orientaciones relacionadas con la COVID-19 y la cadena alimentaria. En primer lugar, tenemos las buenas prácticas de higiene y distanciamiento físico como recomendación general con lavado de manos frecuente, limpieza y desinfección de superficies, uso adecuado de elementos de protección personal, recordando que el uso de guantes no sustituye el lavado de manos, y practicar la etiqueta respiratoria. Igualmente, se resalta la necesidad de capacitar y entrenar al personal en cuanto a la prevención de la propagación de la COVID-19 y el mantenimiento de canales de comunicación para alertar sobre posibles situaciones o condiciones de riesgo.

Durante el transporte y entrega de alimentos se recomienda mantener los contenedores limpios y desinfectados, proteger los alimentos de cualquier contaminación, la desinfección de manos antes de recibir los documentos, el uso de recipientes y materiales de embalaje descartables o la implementación de protocolos de higiene y desinfección para recipientes o embalajes reutilizables, y la limpieza y desinfección frecuente en superficies de alto contacto. Cuando se detecte la presencia de trabajadores con síntomas, este debe comunicarlo de inmediato a su jefe inmediato, seguir las directrices para el registro y rastreo de casos sospechosos, organizar al personal en turnos, limpiar y desinfectar las superficies que estuvieron en contacto con el trabajador infectado, entre las demás medidas de aislamiento, detección y cuarentena que ya conocemos. Lo que conducirá a una gestión adecuada que no implicará el cierre del establecimiento.
Tema central

Situación Nal.

Mortalidad

Trazadores

Brotes

COVID-19

Tablas 
Medidas de prevención a la comunidad por presencia de microrganismos patógenos en alimentos:

\section{sINS}

5 medidas de alta relevancia
Agua y hielo inocuos

Cocción en centro térmico $\geq 74^{\circ} \mathrm{C}$

Separar cocido de cruch Limpieza (manos, materias primas, utensilios y espacios de cocción y
almacenamiento) 8ु)

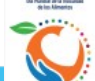

1. Limpieza: Dentro de las cinco medidas de alta relevancia para la inocuidad para prevenir las ETAs, tenemos como base la limpieza no solo de manos sino también de materias primas, utensilios, superficies y lugares de almacenamiento, así como el lavado de manos al cambiar de actividad, por ejemplo, después del cambio de pañales de los bebés o la manipulación de animales como tortugas, reptiles o patos que son vectores importantes de microorganismos patógenos.

2. Separar los alimentos cocidos de los crudos: separar los alimentos crudos de los cocidos, evitar mezclas en ensaladas, el consumo de proteínas crudas o semi crudas. Se recomienda al menos el uso de dos tables, una para alimentos de origen animal y otra para alimentos vegetales, ojalá para alimentos crudos y cocidos, y procurar una higiene adecuada con prácticas de limpieza y desinfección con agentes químicos y agua caliente preferiblemente.

3. Cocción en centro térmico al menos a $74^{\circ} \mathrm{C}$ : Procurar la cocción a por lo menos $74^{\circ} \mathrm{C}$ en el centro térmico del alimento principalmente para alimentos dirigidos a personas de grupos vulnerables como niños, adultos mayores, personas inmunocomprometidas y evitar prácticas gastronómicas que indican que la carne se debe comer medio cocida.

4. Almacenamiento adecuado: Procurar almacenamiento adecuado separando también los crudos de los cocidos, por ejemplo, en la nevera, evitar dejar sobrantes de comida cerca de alimentos crudos, utilizar utensilios para alimentos crudos y cocidos.

5. Agua y hielo inocuos: El agua y el hielo también deben ser inocuos, no solo el agua debe ser potable, el hielo también debe provenir de agua potable, teniendo en cuenta que hay microorganismos que sobreviven a bajas temperaturas.

\section{Referencias:}

World Health Organization -WHO-. Nutrition and Food Safety (NFS) and COVID-19. 2021. Disponible en: https://www.who.int/teams/nutrition-and-food-safety/covid-19

World Health Organization -WHO-. E. coli [Internet]. World Heath Organization. 2020 . Disponible en: https://www.who.int/newsroom/fact-sheets/detail/e-coli

Food and Agriculture Organization -FAO-. Preventing E. coli in food [Internet]. Roma;.. Disponible en: http://www.fao.org/fileadmin/user_ upload/agns/pdf/Preventing_Ecoli.pdf

European Centre for Disease Prevention and Control - ECDC-. Prevention and control measures for Escherichia coli [Internet].

Centers for Disease Control and Prevention -CDC-. Prevention | General Information | Salmonella | CDC [Internet].

Minnesota Department of Health. Preventing Salmonellosis - Minnesota Dept. of Health [Internet]. Minnesota Department of Health. 2019. 


\section{SITUACIÓN NACIONAL}

\section{Tablero de control del análisis de datos de la vigilancia}

Para el análisis de los eventos de mayor notificación en el país, se compara el valor observado en la semana epidemiológica correspondiente, con una línea de base de referencia, que está conformada con la información de esos eventos reportados en 15 intervalos de tiempo de al menos cinco años anteriores.

A partir de semana 14 , se realizan las comparaciones con las vigencias 2015 a 2019, dada la atipicidad presentada para la vigencia 2020. Así se identifica que en la semana epidemiológica 22 el evento morbilidad materna extrema (MME), se encuentra por encima de lo esperado, mientras que los eventos parotiditis, mortalidad perinatal y neonatal tardía, leishmaniasis cutánea, bajo peso al nacer, intoxicaciones y varicela individual, se encuentran por debajo de lo esperado. Los demás eventos están dentro del comportamiento histórico de la notificación (Figura 1).

Figura 1. Comparación de la notificación de casos de eventos priorizados, de alta frecuencia, según su comportamiento histórico. Colombia, a semana epidemiológica 22 de 2021

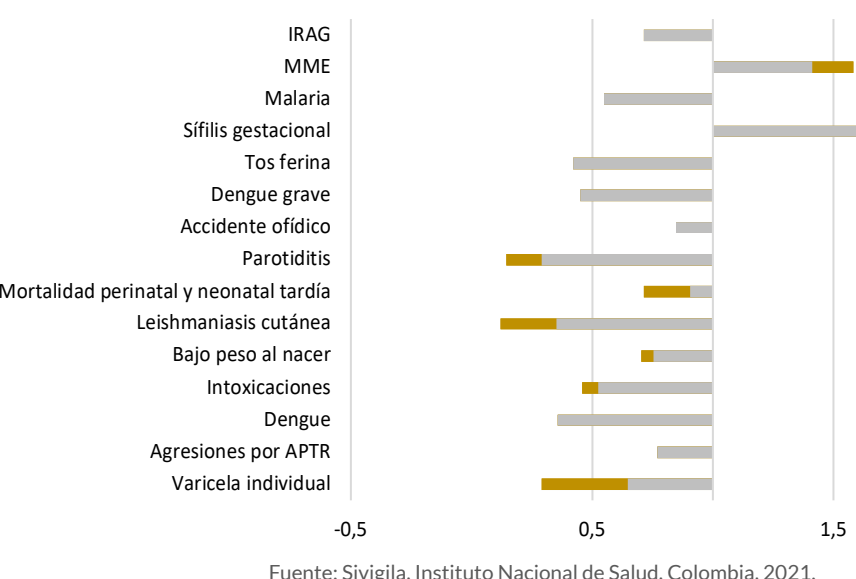

Para el análisis de los eventos de baja frecuencia o raros donde se asume que ocurren de manera aleatoria en el tiempo, se calcula la probabilidad de ocurrencia de cada evento según su comportamiento medio anterior, que para efectos de este análisis es el promedio de casos de 2015 a 2019. Con un nivel de confianza de $p<0,05$ se determina si existen diferencias significativas entre lo observado y lo esperado.

A partir de semana 14, se realizan las comparaciones con las vigencias 2015 a 2019, dada la atipicidad presentada para la vigencia 2020. Para la semana epidemiológica 22, el evento de mortalidad materna presenta un aumento significativo respecto a los valores esperados; los eventos sarampión, leptospirosis, mortalidad por IRA, evento adverso posterior a la vacunación (EAPV), rubeola, lepra, fiebre tifoidea y paratifoidea y tuberculosis farmacorresistente presentan disminución significativa relacionada con el comportamiento de notificación histórico. Los demás eventos se encuentran dentro del comportamiento histórico (Tabla 1).

Tabla 1. Comparación de casos notificados de eventos priorizados, de baja frecuencia, según su comportamiento histórico, Colombia, a semana epidemiológica 22 de 2021

\begin{tabular}{lrrc} 
Evento & Obser-vado & Esperado & \multicolumn{1}{c}{$P$} \\
Mortalidad materna & 18 & 7,4 & 0,00 \\
Sarampión & 13 & 56,8 & 0,00 \\
Leptospirosis & 12 & 50,4 & 0,00 \\
Mortalidad por IRA & 2 & 12,6 & 0,00 \\
EAPV & 3 & 11,4 & 0,00 \\
Rubeola & 5 & 14,4 & 0,00 \\
Lepra & 2 & 8,2 & 0,01 \\
Fiebre tifoidea y paratifoidea & 1 & 5,8 & 0,02 \\
Tuberculosis farmacorresistente & 4 & 8,8 & 0,04 \\
Leishmaniasis mucosa & 0 & 3 & 0,05 \\
Mortalidad por dengue & 0 & 3 & 0,05 \\
Síflis congénita & 23 & 21,6 & 0,08 \\
Mortalidad por EDA 0-4 Años & 1 & 2,4 & 0,22
\end{tabular}

Tema central

Situación Nal.

Mortalidad

Trazadores

Brotes

COVID-19

Tablas 


\section{Cumplimiento en la notificación}

Para esta semana la notificación recibida por el Instituto Nacional de Salud correspondiente a las unidades notificadoras departamentales y distritales (UND) fue del $100 \%$, permaneció igual comparándola con la semana anterior, así como con la misma semana del 2020.

El reporte de las unidades notificadoras municipales (UNM) a nivel nacional fue del $100 \%$ (1 117 / 1117 UNM). Se observa igual con respecto a lo presentado en la semana 21 y frente a la misma semana de 2020 (100\%), el país cumplió con la meta del $97 \%$.

El cumplimiento de las Unidades Primarias Generadoras de Datos (UPGD) esta semana fue de 97,1 \% (5 084 / 5235 UPGD); disminuyó en $0,1 \%$ frente a la semana anterior y aumentó en $0,04 \%$ con respecto a la semana 22 de 2020. Todas las entidades territoriales cumplieron con la meta para este nivel de información. El país cumplió con la meta para la notificación de UPGD,

A continuación se muestra el comportamiento histórico de la notificación por semanas correspondiente a vigencias 2020 y 2021, los cuales se representan en puntos consecutivos y líneas sólidas, respectivamente; se observa las UPGD caracterizadas (líneas amarilla y lila), su comportamiento en la notificación (líneas azul y naranja) y su cumplimiento respecto la notificación de casos (meta $90 \%$ ), (líneas verde y gris); para ambas vigencias en semana 22 se evidencia el cumplimiento del número mínimo de UPGD que deben notificar (Figura 2).

Figura 2. Cumplimiento de la notificación por UPGD, Colombia, semanas epidemiológicas 1 a 22 de 2021
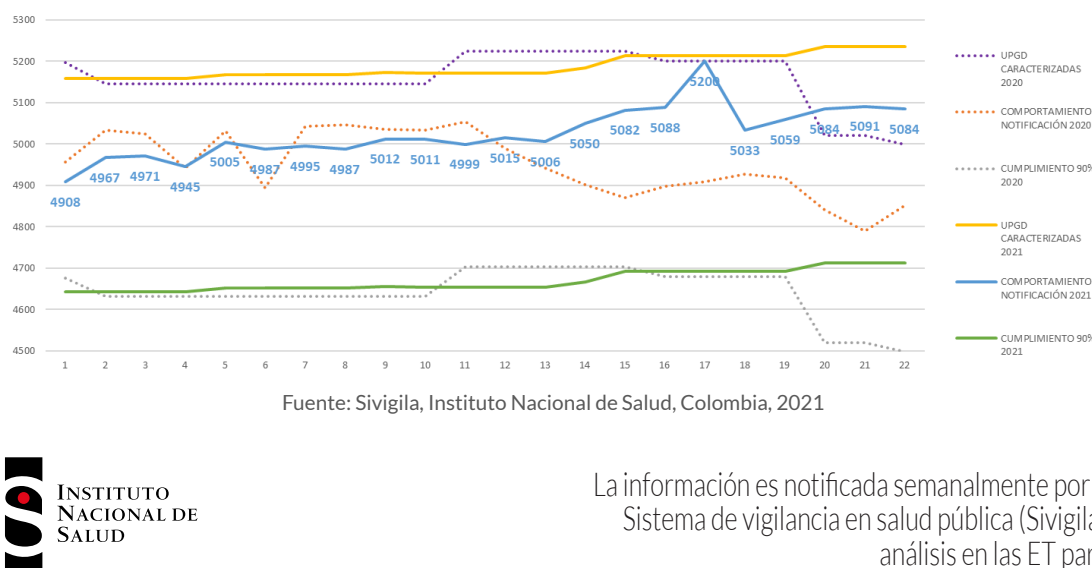

Fuente: Sivigila, Instituto Nacional de Salud, Colombia, 2021

\section{MORTALIDAD}

Mortalidad en menores de 5 años por eventos priorizados

Esta semana se notificaron 12 muertes en menores de 5 años: 10 probablemente asociadas a infección respiratoria aguda, 1 a desnutrición y 1 a enfermedad diarreica aguda

\section{Mortalidad por infección respiratoria aguda}

Se notificaron 10 muertes probablemente asociadas a infección respiratoria aguda en menores de 5 años, 7 correspondientes a esta semana y 3 de semanas anteriores. Para la misma semana epidemiológica de 2020 se notificaron 4 casos.

Para esta semana se observó un aumento en el número de casos en las entidades territoriales de Arauca, Guainía, Risaralda, Santander y Valle del Cauca en comparación con el histórico notificado a semana epidemiológica 22 entre 2014 a 2020, mientras que, en Antioquia, Bogotá, Boyacá, Cali, Cartagena, Cundinamarca, Quindío, Sucre y Vichada se observó una disminución. En las entidades territoriales restantes no se presentaron variaciones.

Figura 3 Entidades territoriales con variaciones significativas en la mediana de casos notificados por mortalidad por infección respiratoria aguda, 2014 a 2020, Colombia, semana epidemiológica 22 de 2021*

$$
\text { Disminución }
$$

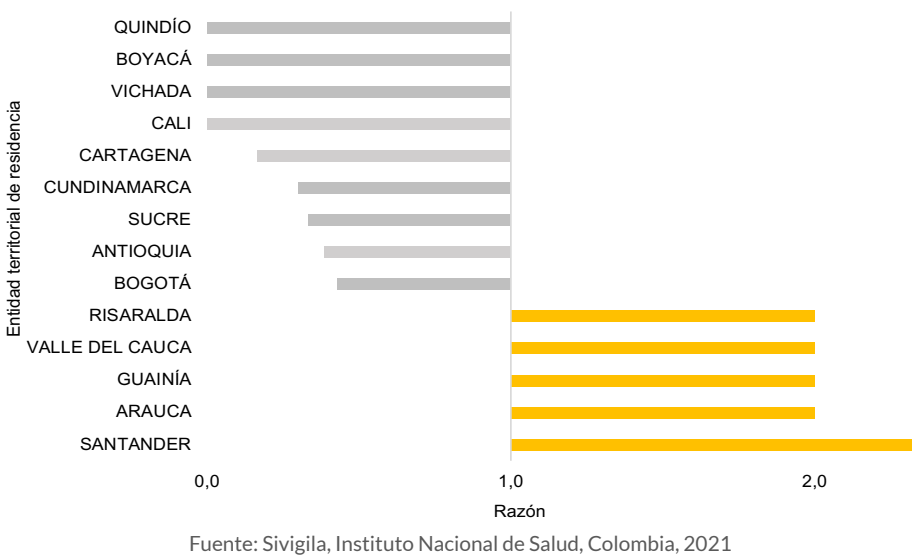

Tema central

Situación Nal.

Mortalidad

Trazadores

Brotes

COVID-19

Tablas 


\section{Mortalidad por desnutrición}

Se notificó 1 muerte probablemente asociada a desnutrición en menor de 5 años, correspondiente a esta semana. Para la misma semana epidemiológica de 2020 se notificaron 4 casos.

Para esta semana se observó un aumento en el número de casos en las entidades territoriales de Arauca, Cartagena, Córdoba y Santa Marta en comparación con el histórico notificado a semana epidemiológica 22 entre 2014 a 2020. En las entidades territoriales restantes no se observaron variaciones.

\section{Mortalidad por enfermedad diarreica aguda}

Se notificó 1 muerte probablemente asociada a enfermedad diarreica aguda en menor de 5 años, correspondiente a esta semana. Para la misma semana epidemiológica de 2020 se notificaron 3 casos.

Para esta semana se observó un aumento en el número de casos en las entidades territoriales de Casanare, Norte de Santander, Santander y Sucre en comparación con el histórico notificado a semana epidemiológica 22 entre 2014 a 2020, mientras que, en Chocó se observó una disminución. En las entidades territoriales restantes no se observaron variaciones.

*Para el análisis de los datos se tomó el comportamiento de cada uno de los eventos a semana epidemiológica 22 entre 2014 a 2020 (histórico) y se comparó con los casos observados a la misma semana epidemiológica del 2021. La razón esperada siempre será 1 y la significancia estadística estará dada por el valor de $p<0,05$ para identificar las entidades territoriales que presentan variaciones estadísticamente significativas.

\section{Mortalidad materna}

En la semana epidemiológica 22 de 2021 se notificaron 249 muertes maternas, 192 corresponden a mortalidad materna temprana (ocurridas durante el embarazo, parto y hasta los 42 días de terminada la gestación), 42 tardías (ocurridas desde el día 43 hasta un año de terminada la gestación) y 15 por causas coincidentes (lesiones de causa externa). Se observa un aumento del $51,1 \%$ en la mortalidad materna temprana respecto al 2020 (Tabla 2).
Buenaventura

Putumayo

Bolívar

Quindío

Barranquilla

Atlántico

Norte de Santander

Antioquia

Valle del Cauca

Arauca

Santander
Sucre

Bogotá

Cartagena

Tolima

215,7
190,9

190,9
185,8

155,5
138,5

134,6
113,4

109,3

94,3

94,3
92,0

88,5

82,2
77,4

77,1
72,7
71,8

71,8
69,0

69,0
65,0
65,0

65,0
64,6

61,8
55,1

55,1
53,0

52,0
50,8

50,8
47,5

46,7

36,3

26,9
26,1

15,5

Fuente: Sivigila, Instituto Nacional de Salud, Colombia, 2021 - DANE, Estadísticas Vitales preliminar 2021
Razón de MM por 100000
Tema centra

Situación Nal.

Mortalidad

Trazadores

Brotes

COVID-19

Tablas 
Para la semana epidemiológica 22 de 2021 se observó un aumento significativo en las muertes maternas tempranas comparado con el promedio histórico en las entidades territoriales de Antioquia, Bogotá, Casanare, Guaviare, Magdalena, Meta, Quindío, Risaralda, Santa Marta y Cali y disminución en la entidad territorial de Cauca (Tabla 4).

Tabla 4. Entidades territoriales con comportamientos inusuales de mortalidad materna temprana respecto al promedio 2017-2020, Colombia, semana epidemiológica 22 de 2021

$\begin{array}{cccc}\text { Entidad territorial de residencia } & \text { Valor observado } & \text { Valor histórico } & \text { Poisson } \\ \text { Antioquia } & 22 & 10 & 0,000 \\ \text { Bogotá } & 18 & 11 & 0,015 \\ \text { Casanare } & 4 & 1 & 0,015 \\ \text { Cauca } & 0 & 4 & 0,018 \\ \text { Guaviare } & 1 & 0 & 0,000 \\ \text { Magdalena } & 14 & 6 & 0,002 \\ \text { Meta } & 7 & 3 & 0,022 \\ \text { Quindío } & 2 & 0 & 0,000 \\ \text { Risaralda } & 5 & 2 & 0,036 \\ \text { Santa Marta } & 8 & 2 & 0,001 \\ \text { Cali } & 8 & 3 & 0,008\end{array}$

En cuanto a las causas de muerte materna temprana el $24,5 \%$ corresponde a causas directas y el $26,0 \%$ a causas indirectas. Las principales causas de muerte materna directa corresponden a trastorno hipertensivo asociado al embarazo con el $11,5 \%$ y la hemorragia obstétrica con el 7,3 \%; la principal causa de muerte indirecta es neumonía por COVID 19 con el 13,5\% (Tabla 5).
Tabla 5. Mortalidad materna temprana por tipo y causa principal agrupada, Colombia, semanas epidemiológicas 01 a 22 de 2021

\begin{tabular}{lrr} 
Causa agrupada & Casos & \\
DIRECTA & $\mathbf{4 7}$ & $\mathbf{2 4 , 5}$ \\
Trastorno hipertensivo asociado al embarazo & 22 & 11,5 \\
Hemorragia obstétrica & 14 & 7,3 \\
Sepsis relacionada con el embarazo & 4 & 2,1 \\
Evento tromboembólico como causa básica & 4 & 2,1 \\
Otras causas directas & 1 & 0,5 \\
Embarazo terminado en aborto con causa directa: hemorragia & 1 & 0,5 \\
Embarazo terminado en aborto con causa directa: sepsis & 1 & 0,5 \\
INDIRECTA & 50 & $\mathbf{2 6 , 0}$ \\
Otras causas indirectas: Neumonía por COVID 19 & 26 & 13,5 \\
Sepsis no obstétrica: Neumonía & 10 & 5,2 \\
Otras causas indirectas & 9 & 4,7 \\
Sepsis no obstétrica & 2 & 1,0 \\
Eventos tromboembólico como causa Básica & 2 & 1,0 \\
Otras causas indirectas: Malaria & 1 & 0,5 \\
EN ESTUDIO & 95 & $\mathbf{4 9 , 5}$ \\
\hline \multicolumn{1}{c}{ Fuente: Sivigila, Instituto Nacional de Salud, Colombia, 2021 } \\
\end{tabular}

Para el análisis de los comportamientos inusuales, por ser la mortalidad materna un evento de baja frecuencia, se usa la distribución de probabilidades de Poisson por medio de la estimación de la probabilidad de ocurrencia del evento según su comportamiento medio entre el 2017 y 2020.

\section{Mortalidad perinatal y neonatal tardía}

A semana epidemiológica 22 de 2021, se han notificado 3523 casos de muerte perinatal y neonatal tardía (MPNT) de los cuales 44 corresponden a casos residentes en el exterior por lo que no se incluyen en el análisis. En esta semana se notificaron 183 casos, 125 corresponden a esta semana y 58 a notificaciones tardías.

En la semana epidemiológica analizada la razón preliminar nacional de mortalidad perinatal y neonatal tardía es de 14,1 muertes por cada 1000 nacidos vivos, en la tabla 1 se observa que en 24 entidades territoriales la razón es superior a la del país. Las 5 entidades territoriales con las razones más altas son Guainía (33,2), Vaupés (30,2), Chocó $(28,5)$, Arauca $(22,6)$, Barranquilla $(21,1)$.
Tema central

Situación $\mathrm{Nal}$

Mortalidad

Trazadores

Brotes

\section{COVID-19}

Tablas 
Tabla 6. Número de casos y razón de mortalidad perinatal y neonatal tardía por entidad territorial de residencia, Colombia, semanas epidemiológicas 01 a 22 de 2021

\begin{tabular}{|c|c|c|}
\hline $\begin{array}{l}\text { Entidad territorial de } \\
\text { residencia }\end{array}$ & $\begin{array}{l}\text { Número de } \\
\text { casos }\end{array}$ & $\begin{array}{l}\text { Razón de Mortalidad perinatal y neonatal } \\
\text { tardía por } 1000 \text { nacidos vivos }\end{array}$ \\
\hline Guainía & 13 & 33,2 \\
\hline Vaupés & 7 & 30,2 \\
\hline Chocó & 63 & 28,5 \\
\hline Arauca & 38 & 22,6 \\
\hline Barranquilla & 171 & 21,1 \\
\hline Córdoba & 192 & 20,2 \\
\hline Bolívar & 115 & 19,1 \\
\hline Sucre & 99 & 18,8 \\
\hline Vichada & 11 & 18,1 \\
\hline Cauca & 127 & 17,9 \\
\hline San Andrés y Providencia & 5 & 17,2 \\
\hline La Guajira & 137 & 16,7 \\
\hline Guaviare & 9 & 16,6 \\
\hline Buenaventura & 29 & 16,4 \\
\hline Quindío & 33 & 15,4 \\
\hline Atlántico & 109 & 15,3 \\
\hline Casanare & 38 & 15,3 \\
\hline Cartagena & 93 & 15,0 \\
\hline Putumayo & 27 & 14,7 \\
\hline Antioquia & 415 & 14,6 \\
\hline Magdalena & 78 & 14,6 \\
\hline Cundinamarca & 204 & 14,4 \\
\hline Risaralda & 55 & 14,4 \\
\hline Nariño & 94 & 14,4 \\
\hline Colombia & 3479 & 14,1 \\
\hline Amazonas & 6 & 14,1 \\
\hline Caldas & 44 & 13,7 \\
\hline Boyacá & 74 & 13,7 \\
\hline Cesar & 118 & 13,6 \\
\hline Cali & 130 & 13,4 \\
\hline Valle del Cauca & 100 & 13,3 \\
\hline Caquetá & 32 & 12,5 \\
\hline Tolima & 79 & 12,5 \\
\hline Norte de Santander & 108 & 11,8 \\
\hline Santa Marta & 40 & 11,3 \\
\hline Huila & 75 & 10,9 \\
\hline Bogotá & 345 & 10,4 \\
\hline Meta & 65 & 10,4 \\
\hline Santander & 101 & 9,5 \\
\hline
\end{tabular}

Fuente: Sivigila, Instituto Nacional de Salud, Colombia, 2021 (Datos preliminares). DANE,

Estadísticas Vitales, Cifras nacimientos marzo 2020 preliminar
Según el momento de ocurrencia de la muerte la mayor proporción son muertes perinatales anteparto con 47,9 \% (1 666), seguido de neonatales tempranas con 27,3\% (950), neonatales tardías con 15,0 $\%$ (521) y perinatales intraparto con $9,8 \%$ (342).

De acuerdo con las causas de muerte agrupadas se observó la mayor proporción en: otras causas de muerte $26,6 \%$, principalmente trastornos de origen perinatal y placentarios, seguido por prematuridad-inmaturidad $24,7 \%$ y asfixia y causas relacionadas $20,4 \%$ (Figura 4 ).

Figura 4. Proporción de causas de muertes perinatales y neonatales tardías por causas de muerte agrupadas, Colombia, semanas epidemiológicas 01 a 22 de 2021

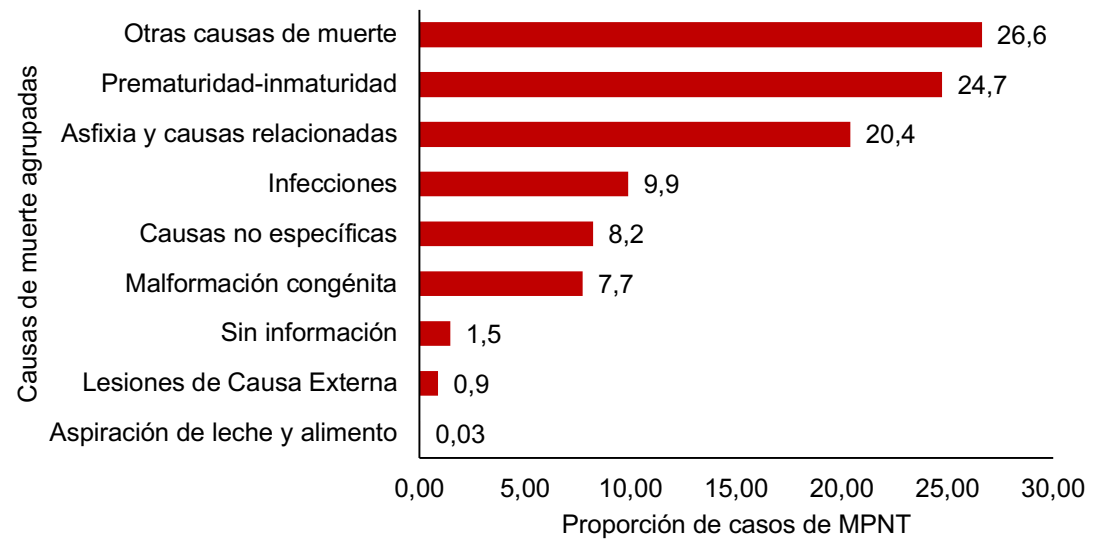

Fuente: Sivigila, Instituto Nacional de Salud, Colombia, 2021 (Datos preliminares).

En lo observado en la semana de análisis, en comparación con lo notificado entre 2016 y 2021, se presenta un incremento en la notificación en Vaupés. Este comportamiento podría estar explicado por las acciones de búsqueda activa institucional que realiza el equipo de vigilancia territorial. Por otra parte, se presenta un decremento en la notificación en Bogotá, Putumayo y Vichada. Comportamiento que podría ser explicado por el subregistro en la notificación de las muertes a Sivigila, respecto al número de muertes certificadas en el Registro Único de Afiliados a la Protección Social-RUAF. 
Dado que el evento tiene una alta frecuencia en notificación y se cuenta con una línea de base estable de más de cinco años, se realiza el análisis de los comportamientos inusuales a través del método: Morbidity and Mortality Weekly Report (MMWR) del Center for Disease Control and Prevention (CDC). Este se basa en la comparación del comportamiento actual del evento en el último periodo epidemiológico (valor observado) con el resultado del promedio de 15 periodos históricos alrededor de ese periodo de evaluación, la ventana histórica de estimación contempla los cinco años previos al año de análisis (Coutin G, Borges J, Batista R, Feal P, Suárez B. Método para el análisis del comportamiento observado de enfermedades seleccionadas con relación al comportamiento histórico. Rev Cubana Hig Epidemiol. 2000;38(3):157-66).

\section{EVENTOS TRAZADORES}

\section{Infección respiratoria aguda}

A nivel nacional se identifica disminución en la notificación para la morbilidad por infección respiratoria aguda (IRA) en los servicios de consulta externa y urgencias; se presenta incremento en las hospitalizaciones por IRAG en sala general y en unidad de cuidados intensivos e intermedios (tabla 7).

Tabla 7. Notificación morbilidad por Infección Respiratoria Aguda por tipo de servicio en Colombia, semanas epidemiológicas 01 a 22, 2020 y 2021

\begin{tabular}{lrrrrl} 
Tipo de servicio & 2020 a semana 21 & 2021 a semana 21 & \multicolumn{2}{c}{ Variación } \\
Consultas externas y urgencias & 2217063 & 1763143 & 20,5 & Disminución \\
Hospitalizaciones en sala general & 74087 & 110959 & 49,8 & Aumento \\
Hospitalizaciones en UCl & 9969 & 39205 & 293,3 & Aumento \\
\hline
\end{tabular}

A semana epidemiológica 22 de 2021, en Colombia se han notificado 1763143 consultas externas y urgencias por IRA, presentando disminución frente a lo notificado a la misma semana de los tres años anteriores con el 20,5\% comparado con 2020, 35,3\% frente a 2019 y $39,5 \%$ frente a 2018 . Teniendo en cuenta el comportamiento de notificación de los últimos siete años, se presenta disminución en 19 entidades territoriales; Cartagena, Córdoba, Guainía y Santa Marta presentan incremento; Arauca, Bolívar, Boyacá, Cundinamarca, La Guajira, Guaviare, Huila, Magdalena, Meta, Norte de Santander, Putumayo, Risaralda, Santander, Sucre y Vichada no presentan comportamientos inusuales.

Por grupos de edad, los adultos de 20 a 39 años representan el 31,5\% (556 145), seguido por el de 40 a 59 años con el 21,7\% (382 180). La mayor proporción de consultas externas y de urgencias por IRA sobre el total de consultas por todas las causas se presenta en los niños de 1 año con el 8,7\% seguido de los menores de 1 año con el 8,0 \%.

En el canal endémico las consultas externas y urgencias por IRA en las semanas trascurridas del año se ubican por debajo del umbral estacional,

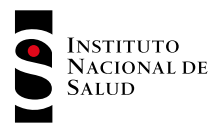


a partir de la semana 02 por debajo del límite inferior hasta la semana 13; desde la semana 14 se observan en zona de seguridad, por encima del límite inferior; para la semana 21 se observa un incremento del 20.1 $\%$ con respecto a la semana anterior y en la semana 22 un descenso del $7,3 \%$ con relación a la semana 21 (figura 5).

Figura 5. Canal endémico de consultas externas y urgencias por infección respiratoria aguda, Colombia, semanas epidemiológicas 01 a 22, entre 2014 y 2021

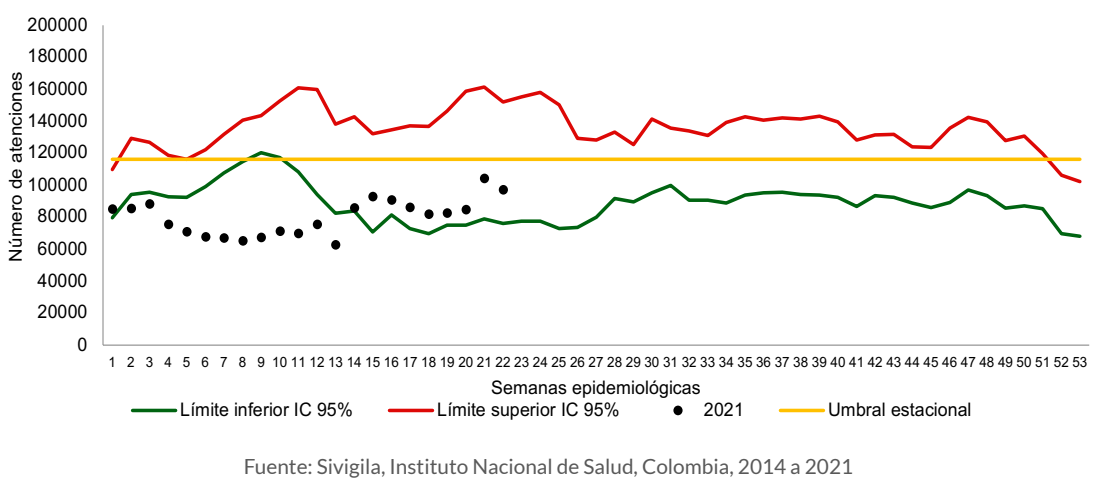

Se notificaron 110959 hospitalizaciones por IRAG en sala general, presentando incremento frente a lo notificado a la misma semana de los tres años anteriores con el $49,8 \%$ frente a 2020, 14,9\% comparado con 2019 y del 6,0 \% frente a 2018. Teniendo en cuenta el comportamiento de notificación de los últimos siete años, se presenta disminución en 8 entidades territoriales, entre las cuales resaltan Vaupés, Caquetá, Quindío y Chocó; e incremento en 16 entidades territoriales resaltando Meta, Bolívar, Huila, Tolima y Cundinamarca; no presentan comportamientos inusuales 14 entidades territoriales.

Por grupos de edad, los adultos de más de 60 años representan el 37,2 \% (41 248), seguido por los de 40 a 59 años con el 23,9\% (26 526). La mayor proporción de hospitalizaciones en sala general por IRAG sobre el total de hospitalizaciones por todas las causas se presenta en los niños de 1 año con el $17,2 \%$, seguido por los niños de 2 a 4 años con el $12,9 \%$.

En el canal endémico durante las cuatro primeras semanas del año las hospitalizaciones por IRAG en sala general se ubicaron por encima del límite superior histórico esperado y el umbral estacional, para la semana 05 se observa un descenso por debajo del umbral estacional, sin variación para las semanas 06 a 08; de las semanas 09 a 12 se ubican en zona de éxito, por debajo del límite interior, a partir de la semana 13 se observa un aumento por encima del umbral estacional; $y$ a partir de la semana 15 se ubican por encima del límite superior histórico establecido (figura 6).

Figura 6. Canal endémico de hospitalizaciones por infección respiratoria aguda grave en sala general, Colombia, semanas epidemiológicas 01 a 22, entre 2014 y 2021

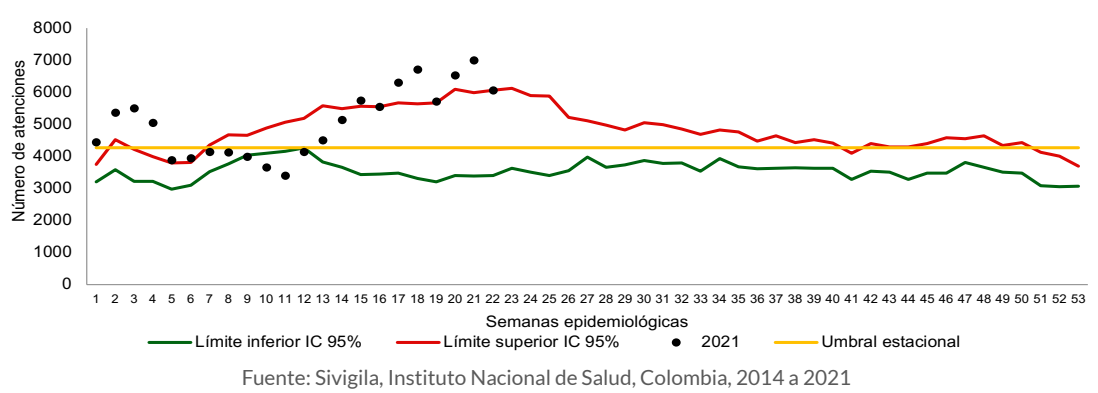

Se notificaron 39205 hospitalizaciones por IRAG en unidad de cuidados intensivos - $\mathrm{UCl}$ e intermedios, presentando incremento frente a lo notificado a la misma semana de los tres años anteriores con el $293,3 \%$ frente a 2020 , $346,3 \%$ comparado con 2019 y $331,3 \%$ frente a 2018 . Se presenta incremento en 32 entidades territoriales, entre las cuales resaltan Valle del Cauca, Caquetá, Antioquia, Nariño, Cundinamarca y Cesar; Arauca presenta disminución y no presentan comportamientos inusuales: Amazonas, Chocó, Córdoba, Guaviare y Vaupés.

Por grupos de edad, los adultos 60 años y más representan el 51,8 \% (20 290), seguido por los de 40 a 59 años con el $30,3 \%$ (11 887) y los de 20 a 39 años con el 8,8 \% (3 447). La mayor proporción de hospitalizaciones por IRAG en UCl e intermedios sobre el total de hospitalizaciones en $\mathrm{UCI}$ por todas las causas se presenta en el grupo de 40 a 59 años con el 34,3\%, seguido por el de mayores de 60 años con el $31,8 \%$.

Paralas 5 primeras semanas las hospitalizaciones por IRAGenUCle intermedios superaron el promedio histórico y el límite superior de las semanas 01 a 53 de 2020, adicionalmente se presenta un incremento progresivo hasta la tercera

Tema central
Situación Nal.
Mortalidad
Trazadores
Brotes

COVID-19

Tablas 
semana y un descenso por siete semanas; durante las siguientes semanas se observa incremento por encima del umbral estacional y a partir de la semana 14 se supera nuevamente el límite superior histórico; en la semana 22 se observa un descenso con respecto a la semana anterior (figura 7).

Figura 7. Comportamiento de hospitalizaciones por infección respiratoria aguda grave en unidades de cuidados intensivos, Colombia, semanas epidemiológicas 01 a 22 , entre 2020 y 2021

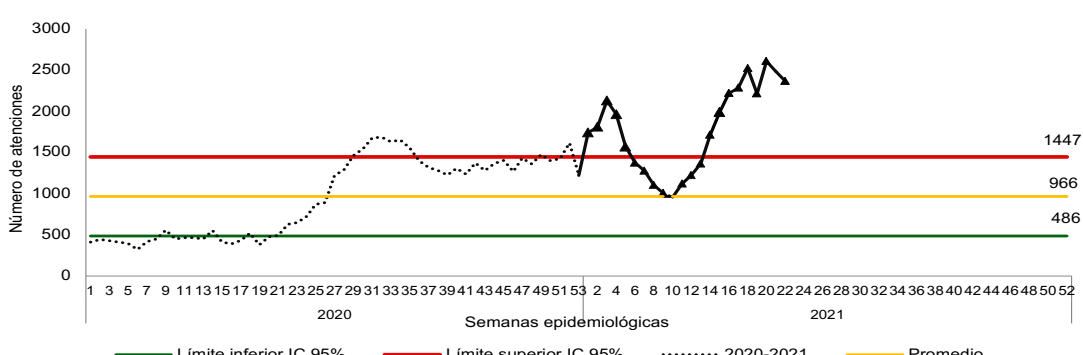

Fuente: Sivigila, Instituto Nacional de Salud, Colombia, 2020 a 2021.

\section{METODOLOGÍA:}

Vigilancia de morbilidad por IRA: los canales endémicos para consultas externas y urgencias y hospitalizaciones en sala general se realizaron con la metodología de Bortman con los datos de la morbilidad por infección respiratoria aguda mediante el cálculo de la media geométrica de los años 2014 a 2020 y el intervalo de confianza.

Para las hospitalizaciones por IRAG en UCl e intermedio se construyó gráfico de control mediante el cálculo del promedio, la desviación estándar y el intervalo de confianza del año anterior.

\section{Dengue}

En la semana epidemiológica 22 de 2021 se notificaron 567 casos probables de dengue: 305 casos de esta semana y 262 casos de semanas anteriores. En el sistema hay 14530 casos, 7627 (52,5\%) sin signos de alarma, 6691 $(46,0 \%)$ con signos de alarma y $212(1,5 \%)$ de dengue grave.

En Colombia, los casos de dengue proceden de 32 departamentos y 5 distritos, distribuidos en 618 municipios. Las entidades territoriales de Cali, Valle del Cauca, Putumayo, Tolima, Cartagena, Huila, Meta, Norte de Santander, Antioquia, Cundinamarca, Cesar, Santander, Barranquilla,
Atlántico, Bolívar, Cauca y Magdalena aportan el 81,6 \% (11 851) de los casos a nivel nacional (tabla 8).

Tabla 8. Casos notificados de dengue por entidad territorial de procedencia y clasificación en Colombia, semanas epidemiológicas 01 a 22 de 2021

\begin{tabular}{|c|c|c|c|c|c|c|}
\hline \multirow{2}{*}{ Entidad territorial } & \multicolumn{2}{|l|}{ Dengue } & \multicolumn{4}{|c|}{ Dengue grave Total } \\
\hline & $\bar{n}$ & $\%$ & $\mathrm{n}$ & $\%$ & $\mathrm{n}$ & $\%$ \\
\hline Cali & 2865 & 20,0 & 31 & 14,6 & 2896 & 19,9 \\
\hline Valle del Cauca & 1307 & 9,1 & 9 & 4,2 & 1316 & 9,1 \\
\hline Putumayo & 770 & 5,4 & 3 & 1,4 & 773 & 5,3 \\
\hline Tolima & 741 & 5,2 & 1 & 0,5 & 742 & 5,1 \\
\hline Cartagena & 685 & 4,8 & 21 & 9,9 & 706 & 4,9 \\
\hline Huila & 658 & 4,6 & 13 & 6,1 & 671 & 4,6 \\
\hline Meta & 658 & 4,6 & 2 & 0,9 & 660 & 4,5 \\
\hline Norte de Santander & 620 & 4,3 & 15 & 7,1 & 635 & 4,4 \\
\hline Antioquia & 493 & 3,4 & 9 & 4,2 & 502 & 3,5 \\
\hline Cundinamarca & 469 & 3,3 & 1 & 0,5 & 470 & 3,2 \\
\hline Cesar & 439 & 3,1 & 22 & 10,4 & 461 & 3,2 \\
\hline Santander & 414 & 2,9 & 6 & 2,8 & 420 & 2,9 \\
\hline Barranquilla & 370 & 2,6 & 10 & 4,7 & 380 & 2,6 \\
\hline Atlántico & 315 & 2,2 & 6 & 2,8 & 321 & 2,2 \\
\hline Bolívar & 304 & 2,1 & 11 & 5,2 & 315 & 2,2 \\
\hline Cauca & 293 & 2,0 & 1 & 0,5 & 294 & 2,0 \\
\hline Magdalena & 279 & 1,9 & 10 & 4,7 & 289 & 2,0 \\
\hline Córdoba & 280 & 2,0 & 3 & 1,4 & 283 & 1,9 \\
\hline Casanare & 279 & 1,9 & 3 & 1,4 & 282 & 1,9 \\
\hline Caquetá & 271 & 1,9 & 3 & 1,4 & 274 & 1,9 \\
\hline Sucre & 251 & 1,8 & 7 & 3,3 & 258 & 1,8 \\
\hline Chocó & 221 & 1,5 & 1 & 0,5 & 222 & 1,5 \\
\hline Nariño & 198 & 1,4 & 6 & 2,8 & 204 & 1,4 \\
\hline Amazonas & 180 & 1,3 & 0 & 0,0 & 180 & 1,2 \\
\hline Santa Marta & 171 & 1,2 & 7 & 3,3 & 178 & 1,2 \\
\hline Boyacá & 172 & 1,2 & 0 & 0,0 & 172 & 1,2 \\
\hline Buenaventura & 114 & 0,8 & 1 & 0,5 & 115 & 0,8 \\
\hline Arauca & 97 & 0,7 & 0 & 0,0 & 97 & 0,7 \\
\hline Quindío & 81 & 0,6 & 2 & 0,9 & 83 & 0,6 \\
\hline Risaralda & 82 & 0,6 & 1 & 0,5 & 83 & 0,6 \\
\hline Caldas & 77 & 0,5 & 0 & 0,0 & 77 & 0,5 \\
\hline La Guajira & 36 & 0,3 & 5 & 2,4 & 41 & 0,3 \\
\hline Exterior & 37 & 0,3 & 1 & 0,5 & 38 & 0,3 \\
\hline Archipiélago de San Andrés & 32 & 0,2 & 0 & 0,0 & 32 & 0,2 \\
\hline Guaviare & 28 & 0,2 & 0 & 0,0 & 28 & 0,2 \\
\hline Vichada & 18 & 0,1 & 0 & 0,0 & 18 & 0,1 \\
\hline Guainía & 11 & 0,1 & 1 & 0,5 & 12 & 0,1 \\
\hline Vaupés & 2 & 0,0 & 0 & 0 & 2 & 0,0 \\
\hline Total & 14318 & 100 & 212 & 100 & 14530 & 100 \\
\hline
\end{tabular}


El 62,4\% (9 061) de los casos de dengue se reportó en 42 municipios, con mayor frecuencia en: Cali, con 19,9 \% (2 896); Cartagena, con el 4,9 \% (706); Cúcuta, con el 2,7\% (398); Barranquilla, con 2,6 \% (380); Orito - Putumayo, con el 1,8 \% (264); Villavicencio - Meta, con el 1,5 \% (222); Yumbo - Valle del Cauca (196), Ibagué - Tolima (192) y Neiva - Huila (191), con el 1,3\% cada uno; Santa Marta (178) y Aguachica Cesar (177), con 1,2 \% cada uno; Villagarzón - Putumayo (164) y Leticia - Amazonas (156), con el 1,1\% cada uno.

Se hospitalizó el 76,3\% (5 102) de los casos de dengue con signos de alarma y el 92,0 \% (195) de dengue grave; las entidades notificadoras que hospitalizaron menos del $60,0 \%$ de los casos de dengue con signos de alarma fueron: Boyacá, Cauca, Valle del Cauca, Caldas, Buenaventura, Guaviare, Guainía, Bolívar y Chocó; y las entidades notificadoras que no hospitalizaron el $100 \%$ de los casos de dengue grave fueron: Cesar, Cali, Huila, Santa Marta, Cartagena, Magdalena, Santander, La Guajira, Valle del Cauca, Quindío y Cundinamarca.

A semana 22 se ha confirmado el 41,2\% (5 990) de los casos de dengue notificados, según clasificación se confirmó el 49,3 \% (3 296) de los casos de dengue con signos de alarma y $61,8 \%$ (131) de los casos de dengue grave. Las entidades que han confirmado el 100,0 \% de los casos de dengue con signos de alarma notificados son Buenaventura y Vichada; mientras que, Buenaventura, Caquetá, Chocó, Córdoba y Cundinamarca, han confirmado el $100 \%$ de los casos de dengue grave notificados.

La incidencia nacional de dengue es de 47,0 casos por cada 100000 habitantes en riesgo. En las entidades de Amazonas, Putumayo, Cali, Caquetá, Cundinamarca, Cartagena, Casanare y Valle del Cauca se estiman tasas de incidencia superiores a 70,0 casos por 100000 habitantes (figura 8).
Figura 8. Incidencia de dengue por entidad territorial de procedencia en Colombia, semana epidemiológica 21 de 2021

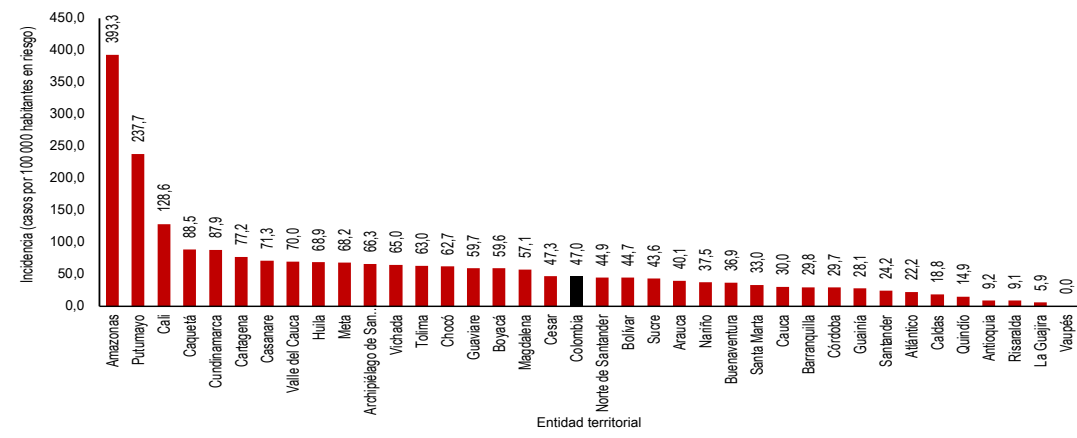

Fuente: Sivigila, Instituto Nacional de Salud, Colombia, 2021

A semana epidemiológica 22 de 2021, el evento a nivel nacional presentó un comportamiento dentro de lo esperado, comparado con su comportamiento histórico (figura 9).

Figura 9. Canal endémico nacional de dengue en Colombia, semana epidemiológica 22, 2021

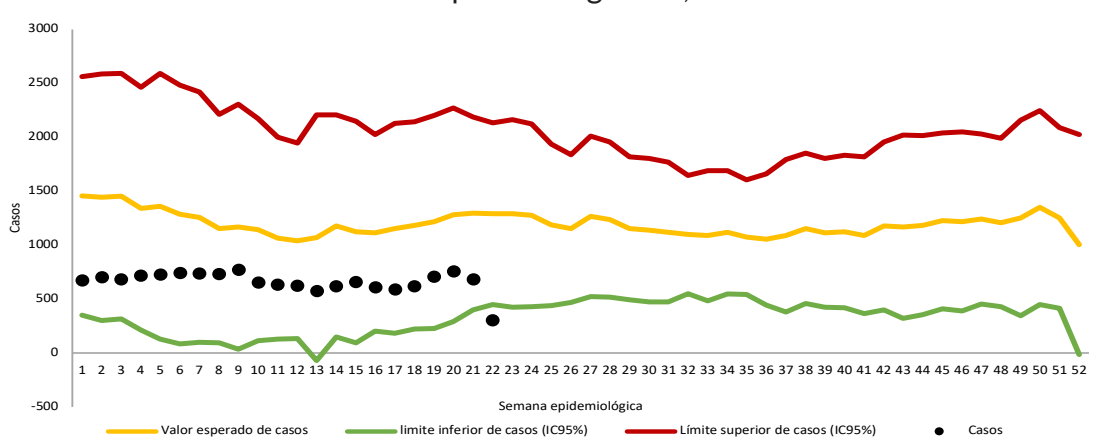

Fuente: Sivigila, Instituto Nacional de Salud, Colombia, 2021

De acuerdo con la situación epidemiológica según canal endémico, 1 entidad por debajo de lo esperado, 22 entidades territoriales se encuentran dentro de lo esperado, 7 entidades se encuentran en situación de alerta y 7 entidades con presentación de casos por encima del valor esperado, comparado con el comportamiento histórico (tabla 9). 
Tabla 9. Comportamiento epidemiológico de dengue por entidad territorial de procedencia, Colombia, semanas epidemiológicas 19 a 21 de 2021

\begin{tabular}{llll}
\hline $\begin{array}{l}\text { Comportamiento } \\
\text { epidemiológico }\end{array}$ & \multicolumn{3}{l}{ Entidad territorial } \\
\hline Por debajo de lo esperado & Tolima & & \\
\hline Dentro del número & Antioquia & Arauca & Atlántico \\
esperado de casos & Bolívar & Boyacá & Caldas \\
& Cali & Casanare & Cundinamarca \\
& Guainía & Guaviare & Huila \\
& La Guajira & Meta & Nariño \\
& Quindío & Risaralda & Santander \\
& Sucre & Vaupés & Vichada \\
& San Andrés, Providenciay Santa Catalina & \\
\hline Situación de alerta & Barranquilla & Caquetá & Cesar \\
& Córdoba & Norte de Santander & Putumayo \\
& Valle del Cauca & Buenaventura & Cartagena \\
\hline Por encima del número & Amazonas & Chocó & Magdalena \\
\hline esperado de casos & Cauca & & \\
\cline { 2 - 4 } & Santa Marta & & \\
\hline
\end{tabular}

Fuente: Sivigila, Instituto Nacional de Salud, Colombia 2021

Durante el 2021 se han notificado 48 muertes probables por dengue, de las cuales 8 han sido confirmadas, procedentes de: Cartagena, con 5 casos; Atlántico, Barranquilla y Córdoba, con 1 caso cada uno. Se han descartado 10 casos y se encuentran en estudio 30 muertes procedentes de: Cesar y Magdalena, con 4 casos cada uno; Huila, con 3 casos; Antioquia, Barranquilla, Bolívar, Cali, Quindío, Santa Marta y Valle del Cauca, con 2 casos cada uno; Casanare, Nariño, Tolima, Vaupés y Exterior, con 1 caso cada uno.

\section{Metodología}

Se realizó un informe descriptivo de los casos notificados durante la semana epidemiológica 22 de 2021, teniendo en cuenta las variables de tiempo, persona y lugar contenidas en la ficha de datos básicos y complementarios del evento de dengue, dengue grave y mortalidad por dengue (Código INS 210, 220 y 580). Los indicadores se presentan en distribuciones de frecuencias en figuras y tablas.

El canal endémico nacional y el análisis de comportamiento epidemiológico por entidad territorial se realizó con la metodología de medias geométricas (Marcelo Bortman), estableciendo los siguientes límites de control: por debajo de lo esperado, número de casos menor al límite inferior IC95\%; dentro de lo esperado, número de casos entre el límite inferior y la media geométrica IC95\%; en alerta, número de casos entre la media geométrica y el límite superior IC $95 \%$, e incremento por encima de lo esperado, número de casos por encima del límite superior IC95\%.

En el análisis del comportamiento de dengue por canal endémico no se tiene en cuenta la semana epidemiológica actual dado que, el periodo de incubación del virus de dengue es de 3 a 14 días, por lo tanto, los casos de esta semana se reflejarán plenamente en la siguiente semana.

\section{Malaria}

\section{Análisis epidemiológico nacional}

Según el análisis del último periodo epidemiológico, el país se encuentra en situación de seguridad para malaria, como lo muestra el canal endémico (Figura 10).

Figura 10. Canal endémico de malaria, Colombia, semana epidemiológica 22, 2021

$$
2500
$$

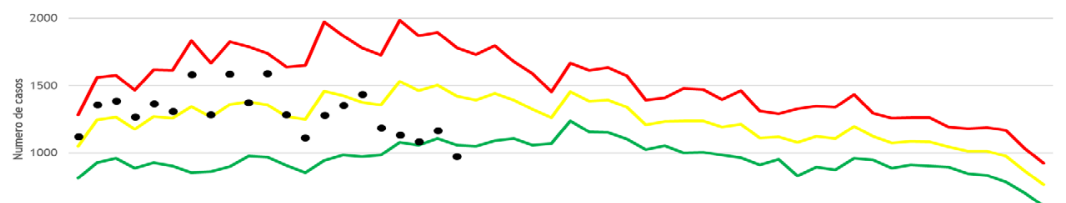

500

\section{2 Fuente: Sivigila, Instituto Nacional de Salud, Colombia 2021 \\ Nota: La información de brotes y alertas se analiza teniendo en cuenta las úttimas cuatro semanas Epidemiológicas; el canal endémico se analiza por el método de media geométrica.}

En la semana epidemiológica 22 se notificaron 1297 casos de malaria, teniendo un acumulado de 27991 casos, de los cuales 27 465 son de malaria no complicada y 526 de malaria complicada. Predomina la infección por Plasmodium falciparum (P. falciparum) con $51,3 \%$ (14 361), seguido de Plasmodium vivax ( $P$. vivax) con 47,9 \% (13 406) e infección mixta con 0,8 \% (224).

\section{Malaria no complicada}

Por procedencia, Chocó (30,0 \%), Nariño (24,4\%), Córdoba (12,4\%), Antioquia (9,8\%) y Guainía (4,7\%) aportan el $81,3 \%$ de los casos de malaria no complicada (Tabla 10).

\section{Tema central \\ Situación Nal. \\ Mortalidad \\ Trazadores \\ Brotes \\ COVID-19}

Tablas 
Tabla 10. . Casos notificados de malaria no complicada por entidad territorial de procedencia. Colombia, semanas epidemiológicas 01 a 21 de 2021

\begin{tabular}{|c|c|c|c|c|c|c|}
\hline Entidad territorial & Infección mixta & P. falciparum & P. malarie & P. vivax & $\mathrm{n}$ & $\%$ \\
\hline Chocó & 77 & 4210 & 0 & 3598 & 7885 & 30,10 \\
\hline Nariño & 22 & 5815 & 0 & 651 & 6488 & 24,80 \\
\hline Córdoba & 11 & 654 & 0 & 2512 & 3177 & 12,10 \\
\hline Antioquia & 17 & 765 & 0 & 1757 & 2539 & 9,70 \\
\hline Cauca & 1 & 1180 & 0 & 19 & 1200 & 4,60 \\
\hline Guainía & 4 & 88 & 0 & 1102 & 1194 & 4,60 \\
\hline Vichada & 23 & 156 & 0 & 487 & 666 & 2,50 \\
\hline Buenaventura & 3 & 476 & 0 & 74 & 553 & 2,10 \\
\hline Norte de Santander & 1 & 1 & 0 & 508 & 510 & 1,90 \\
\hline Guaviare & 2 & 70 & 0 & 397 & 469 & 1,80 \\
\hline Risaralda & 3 & 16 & 0 & 358 & 377 & 1,40 \\
\hline Bolívar & 24 & 51 & 0 & 270 & 345 & 1,30 \\
\hline Exterior & 4 & 29 & 0 & 236 & 269 & 1,03 \\
\hline Meta & 0 & 32 & 0 & 188 & 220 & 0,80 \\
\hline Amazonas & 0 & 3 & 0 & 113 & 116 & 0,40 \\
\hline Casanare & 0 & 0 & 0 & 59 & 59 & 0,20 \\
\hline Vaupés & 0 & 1 & 0 & 20 & 21 & 0,10 \\
\hline Cali & 1 & 9 & 0 & 6 & 16 & 0,10 \\
\hline Putumayo & 0 & 1 & 0 & 12 & 13 & 0,00 \\
\hline Valle del Cauca & 0 & 4 & 0 & 6 & 10 & 0,00 \\
\hline Sucre & 0 & 1 & 0 & 9 & 10 & 0,00 \\
\hline Desconocido & 0 & 3 & 0 & 6 & 9 & 0,03 \\
\hline Santander & 1 & 1 & 0 & 6 & 8 & 0,00 \\
\hline La Guajira & 0 & 0 & 0 & 6 & 6 & 0,00 \\
\hline Arauca & 0 & 0 & 0 & 5 & 5 & 0,00 \\
\hline Cesar & 2 & 0 & 0 & 3 & 5 & 0,00 \\
\hline Cartagena & 0 & 0 & 0 & 4 & 4 & 0,00 \\
\hline Huila & 0 & 0 & 0 & 3 & 3 & 0,00 \\
\hline Caquetá & 0 & 1 & 0 & 1 & 2 & 0,00 \\
\hline Magdalena & 0 & 1 & 0 & 1 & 2 & 0,00 \\
\hline Barranquilla & 1 & 0 & 0 & 0 & 1 & 0,00 \\
\hline Atlántico & 0 & 0 & 0 & 1 & 1 & 0,00 \\
\hline Total & 197 & 13568 & 0 & 12419 & 26184 & 100 \\
\hline
\end{tabular}

\section{Malaria Complicada}

Se notificaron 526 casos de malaria complicada, que proceden de 22 entidades territoriales y 7 casos provienen del exterior. Nariño, Antioquia, Chocó, Córdoba, Cauca, Meta y Vichada notifican el 81,5\% de los casos.
De los casos de malaria complicada el 59,5\% (313) corresponde a hombres. El 30,8 \% (162) se presenta en personas de 15 a 24 años y el 18,6 \% (98) ocurre en indígenas. Por lugar de procedencia, el $41,9 \%$ (220) proviene de rural disperso. Por régimen de afiliación, el 65,6 \% (345) pertenece al régimen subsidiado.

De los casos de malaria complicada causados por P. vivax o P. falciparum, el 78,7 \% (414) presentó complicaciones hematológicas, el 17,1 \% (90) complicaciones hepáticas, el 5,1\% (27) complicaciones renales, el 2,9\% (15) complicaciones pulmonares y el 2,5\% (13) malaria cerebral (Figura 11).

Figura 11. Tipo de complicaciones de malaria, Colombia, semanas epidemiológicas 01 a 22 de 2021

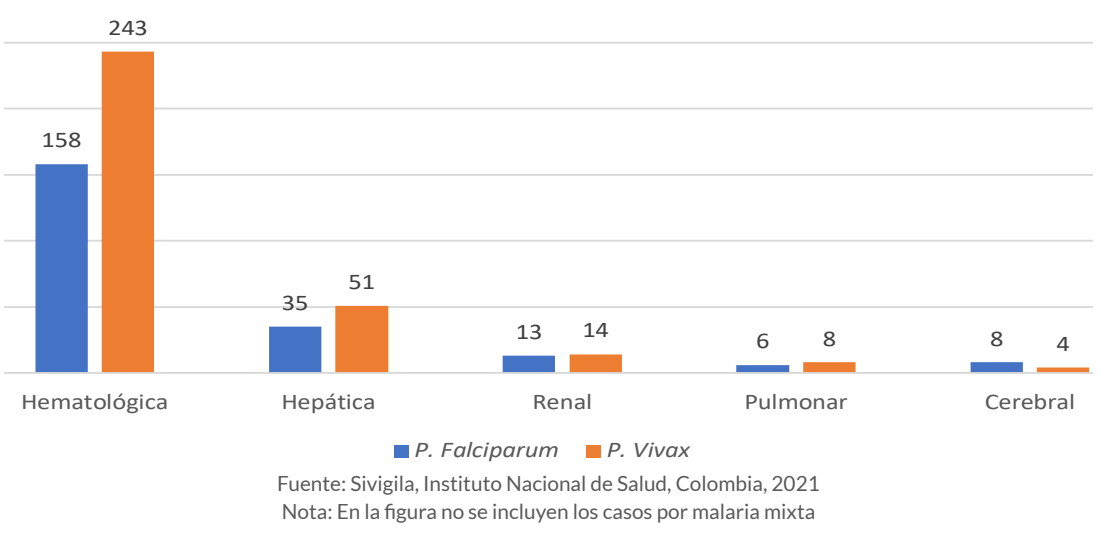

\section{Comportamientos inusuales}

A semana epidemiológica 22, ningún departamento está por encima del número esperado de casos y dos departamentos están en situación de alerta para malaria (Tabla 11). 
Tabla 11. Distribución de entidades territoriales según el comportamiento epidemiológico de malaria, Colombia, semana epidemiológica 22 de 2021

\begin{tabular}{llll}
\hline Comportamiento epidemiológico & Departamentos & & \\
\cline { 1 - 1 } Menor al comportamiento histórico & Amazonas & Antioquia & Chocó \\
& & Bolívar \\
\hline En el comportamiento histórico & La Guajira & Arauca & Atlántico \\
& Caquetá & Quindío & Caldas \\
& Huila & Sucre & Magdalena \\
& Cesar & Chocó & Santander \\
& Risaralda & Vichada & Cauca \\
& Valle del Cauca & Putumayo & Bolívar \\
& Guainía & Norte de Santander & Vaupés \\
& Casanare & Guaviare & Risaralda \\
& & & Córdoba \\
\hline Situación de alerta & Meta & Nariño & \\
\hline Mayor al comportamiento histórico & & \\
\hline \multicolumn{4}{c}{ Fuente: Sivigila, Instituto Nacional de Salud, Colombia 2021 } \\
Nota: La información de brotes yalertas se analiza teniendo en cuenta las últimas cuatro semanas epidemiológicas
\end{tabular}

A semana epidemiológica 22, 11 municipios se encuentran en situación de brote; los que más reportan casos son: Olaya Herrera y Mosquera (Nariño) y Medio San Juan (Chocó) (Tabla 12).

Tabla 12. Municipios en situación de brote por malaria a semana epidemiológica 22 en Colombia, 2021

\begin{tabular}{lcccc} 
Departamento & Municipio & Acumulado & Esperado & Observado \\
\cline { 2 - 5 } Nariño & Olaya Herrera & 1094 & 119 & 318 \\
Nariño & Mosquera & 607 & 44 & 102 \\
Chocó & Medio San Juan & 579 & 75 & 134 \\
Antioquia & Murindó & 249 & 19 & 41 \\
Nariño & La Tola & 228 & 11 & 48 \\
Córdoba & Montería & 178 & 3 & 37 \\
Chocó & Litoral Del Bajo San Juan & 153 & 13 & 42 \\
Meta & Mapiripán & 103 & 6 & 12 \\
Guaviare & Calamar & 94 & 8 & 22 \\
Chocó & Unión Panamericana & 84 & 18 & 30 \\
Meta & Puerto López & 11 & 1 & 4
\end{tabular}

Nota: La información de brotes y alertas se analiza teniendo en cuenta las últimas cuatro semanas epidemiológicas

\section{Comportamientos inusuales (municipios IREM)}

La Iniciativa Regional para la Eliminación de la Malaria (IREM) se implementa en doce municipios del Pacífico colombiano, con el objetivo de reducir y eliminar la transmisión de la malaria. Busca fortalecer la red de diagnóstico para propender por un diagnóstico y tratamiento oportuno de casos de malaria, plantea la vigilancia en salud pública como intervención en salud pública y busca cortar cadenas de transmisión.

A semana epidemiológica 22, de los 12 municipios en los que se implementa la IREM, según el análisis de comportamientos inusuales, ninguno se encuentra en incremento. Se encuentran en decremento: Acandí, Atrato, Bagadó, Juradó, Lloró, Medio Atrato, Quibdó, Río quito, Riosucio, Unguía, Buenaventura y Tumaco, ninguno se encuentra en situación de brote.

Tabla 13. Comportamientos inusuales, municipios Iniciativa Regional para la Eliminación de la Malaria, semana epidemiológica 22, Colombia, 2021

\begin{tabular}{llllllll}
\hline Departamento & Municipios & Acumulado & Esperado & Observado & $\begin{array}{c}\text { Comportamiento } \\
\text { inusual }\end{array}$ & $\begin{array}{c}\text { Situación } \\
\text { epidemiológica }\end{array}$ \\
& Acandí & 14 & 4 & 0 & Disminución & Éxito \\
& Atrato & 184 & 53 & 25 & Disminución & Seguridad \\
& Bagadó & 379 & 96 & 67 & Disminución & Seguridad \\
& Juradó & 13 & 9 & 3 & Disminución & Seguridad \\
\multirow{5}{*}{ Chocó } & Lloró & 210 & 206 & 35 & Disminución & Éxito \\
& Medio Atrato & 234 & 101 & 25 & Disminución & Éxito \\
& Quibdó & 1635 & 730 & 148 & Disminución & Éxito \\
& Río Quito & 116 & 78 & 12 & Disminución & Éxito \\
& Ríosucio & 63 & 14 & 3 & Disminución & Seguridad \\
& Unguía & 9 & 10 & 3 & Disminución & Seguridad \\
\hline Buenaventura & Buenaventura & 603 & 136 & 113 & Disminución & Seguridad \\
\hline Nariño & Tumaco & 764 & 160 & 60 & Disminución & Éxito \\
\hline \multicolumn{5}{c}{ Nota: La información de brotes yalertas se analiza teniendo en cuentalas últimas cuatro semanas epidemiológicas }
\end{tabular}

Metodología

Se realizó un análisis descriptivo con corte a semana epidemiológica 22 de 2021, con información que incluye: descripción de los casos en tiempo, lugar y persona, análisis de tendencia, comportamientos inusuales, descripción y análisis de indicadores para la vigilancia.
Tema central

Situación Nal.

Mortalidad

Trazadores

Brotes

COVID-19

Tablas 


\section{BROTES Y SITUACIONES DE EMERGENCIA EN SALUD PÚBLICA}

\section{ALERTAS NACIONALES}

\section{Situación medio ambiental Arauca. Junio 10 de 2021}

Las prolongadas Iluvias en el departamento de Arauca han afectado principalmente los municipios de Fortul y Saravena, donde se han presentado inundaciones, destrucción de vías, viviendas, perdidas de cultivos y ganado. En Saravena se encuentran aproximadamente 400 familias damnificadas y se ha establecido un Alojamiento Temporal de Emergencia - ATE. El municipio de Fortul cuenta con dos ATE los cuales albergan 350 personas. La caracterización de la población en los ATE se encuentra en proceso.

El programa de salud ambiental ha venido adelantando acciones de inspección, vigilancia y control sobre las condiciones sanitarias de los ATE de Saravena y Fortul, estos cuentan con agua potable apta para el consumo, unidades sanitarias en buenas condiciones y adecuado manejo de los residuos sólidos y líquidos. Las unidades sanitarias se componen de baños, duchas y lavamanos en buenas condiciones, pero insuficientes, por tal razón se han instalado baños portátiles. Los residuos sólidos son recogidos según la programación y rutas establecidas por la Empresa de Servicios Públicos de Fortul. Se cuenta con Plan de distribución diaria de alimentos en los 2 ATE por parte del municipio de Fortul.

Dentro de las acciones se encuentra pendiente la activación de la vigilancia sindrómica con el fin de identificar eventos de interés en salud pública (Enfermedad diarreica aguda, Infección respiratoria aguda, Infecciones transmitidas por alimentos, dengue, malaria, hepatitis $A$, Covid-19, varicela, violencia de género, intoxicación por sustancias químicas, intento de suicidio, morbilidad materna extrema y mortalidad materna) y dar respuesta oportunamente. Se está a la espera de los reportes de parte de los municipios, ya que de acuerdo con estos se activan los planes de estrategias de respuestas y planes de contingencia. Situación en seguimiento.

Fuente: SITREP 01. Ola Invernal Arauca. Unidad Administrativa Especial de Salud de Arauca. Junio 8 de 2021.

\section{Actualización Situación Alojamientos Temporales de Emer- gencia - ATE. Arauquita - Arauca. Junio 10 de 2021.}

Se recibió información desde la Unidad Administrativa Especial de Salud de Arauca, sobre situación de los ATE en Arauquita, en donde hasta el momento se presentan seis ATE activos en los cuales se encuentran albergadas 169 familias, para un total de 526 personas, de las cuales 260 son hombres, 266 son mujeres entre ellas 10 gestantes, 76 niños menores de 5 años, 132 niños entre 5 a 14 años, 279 personas entre 15 y 54 años y 39 adultos mayores de 55 años. Con respecto a Covid 19, se han tomado y procesado 688 muestras con 133 resultados positivos. Con corte a 4 de junio de 2021 se caracterizaron 16 conglomerados en los ATE, se cerraron 14 y se encuentran abiertos los conglomerados Gabriel García Márquez y 18 de enero. El 4 de junio de 2021 comenzó el retorno masivo de la población a Venezuela. Situación en seguimiento.

Fuente: SITREP 22. Unidad Administrativa Especial de Salud de Arauca. Junio 9 de 2021.

\section{Eventos de control internacional}

En Colombia en la semana epidemiológica 23 no se reportaron casos o alertas de enfermedad por el virus Ébola, peste bubónica/ neumónica ni carbunco; sin embargo, se continúa el monitoreo de alertas y el fortalecimiento de acciones de vigilancia, notificación y respuesta a nivel nacional y subnacional. 


\section{ALERTAS INTERNACIONALES}

Actualización epidemiológica semanal sobre COVID-19. Fecha de Publicación 8 de junio de 2021. Organización Mundial de la Salud (OMS)

El número de casos y muertes de COVID-19 a nivel mundial continúan disminuyendo, más de 3 millones de casos nuevos un poco más 73000 muertes, con una disminución del $15 \%$ y $8 \%$ respectivamente, comparado con la semana anterior. La región europea y el Sudeste Asiático reportaron una marcada disminución de nuevos casos y muertes; mientras que la región de África informó de un aumento en comparación con la semana anterior. El número de casos en región de las Américas y el Mediterráneo Oriental y el Pacífico Occidental fueron similares a lo reportado en las semanas anteriores. La región del Pacifico Occidental reporto el mayor incremento en el número de muertes, la incidencia de muertes se mantuvo estable en la Región de las Américas, así como en las regiones del Mediterráneo Oriental y África. A pesar de una tendencia global a la baja en las últimas cuatro semanas la incidencia de casos por $\mathrm{CO}$ VID-19 sigue siendo alta y se han observado aumentos sustanciales en muchos países de todo el mundo.

El mayor número de nuevos casos se reportaron en la India (914539 nuevos casos; disminución del 33\%), Brasil (449 478 casos nuevos; incremento del 7\%), Argentina (212 975 nuevos casos; disminución del 3\%), Colombia (175 479 nuevos casos, aumento del 17\%) y Estados Unidos (99 103 casos nuevos; disminución del 35\%).

\section{Variantes SARS-CoV-2}

Las actividades de vigilancia para la detección de variantes de SARS-CoV-2 se han fortalecido a nivel local y nacional, incluidas las estrategias de secuenciación genómica, el número de países/ territorios/áreas que reportan variantes de interés y variantes de preocupación (VOI y VOC por sus siglas en ingles respectivamente) continúa incrementando. Hasta el 8 de junio, un total de 161 países han reportado la variante Alfa, 115 países la variante Beta, 64 países la variante Gamma, 74 países reportaron la variante Delta, de esta última 12 no se ha identificado el sub-linaje. La información presentada debe ser interpretada de acuerdo con las limitaciones de la vigilancia incluidas la capacidad de secuenciación y priorización de muestras entre los diferentes países.

\section{Panorama regional de la OMS}

Región de África. La región reportó alrededor de 66000 casos nuevos con un incremento del $25 \%$ y más de 1100 nuevas muertes con disminución de $4 \%$ comparado con la semana anterior. Las incidencias de casos aumentaron en un $20 \%$. El mayor número de casos nuevos se notificó en Sudáfrica (32 421 nuevos casos, incremento del $22 \%$ ), Uganda (5 745 casos nuevos, incremento del 137\%) y Zambia (4 789 casos, incremento del $191 \%$ ). El mayor número de nuevas muertes se registró en Sudáfrica (566 muertes, disminución del $4 \%$ ), (Kenya 123 nuevas muertes, incremento del 34\%) y Namibia (87 nuevas muertes, incremento del 58\%)

Región de las Américas. La región ha reportado más de 1,2 millones de casos nuevos y más de 34000 nuevas muertes, la incidencia general de los casos y muertes se han mantenido estables en las últimas semanas, sin embargo, se han observado aumentos considerables en varios países. El mayor número de caso nuevos se reportó en Brasil (449 478 casos nuevos; incremento del 7\%), Argentina (212 975 nuevos casos; incremento del 3\%), y Colombia (175 479 casos nuevos; incremento del 17\%). El mayor número de nuevas muertes se registró en Brasil (11 797 nuevas muertes; disminución del 7\%), México (5 496 nuevas muertes, aumento del 203\%) y Argentina (3 718 nuevas muertes; incremento del 13\%).

Región del Mediterráneo Oriental. La región notificó alrededor de 202000 nuevos casos y más de 43500 nuevas muertes, la incidencia semanal de casos y muertes ha continuado una tendencia a la baja; sin embargo, siguen los incrementos observados en varios países de la región. El mayor número de casos nuevos se notificó en República Islámica de Irán (67533 casos nuevos; con una disminución del 3\%\%), Iraq (28 070 casos nuevos; disminución del 5\%) y Pakistán (14 272 casos nuevos; disminución del 25\%). El mayor número de nuevas muertes se registró en la República Islámica de
Tema centra

Situación $\mathrm{Nal}$

Mortalidad

Trazadores

Brotes

COVID-19

Tablas 
Irán (1 200 nuevas muertes; disminución del 12\%), Pakistán (509 nuevas muertes; similar a la semana anterior) y Túnez (374 nuevas muertes; una disminución del $5 \%$ ).

Región Europea. La región ha reportado cerca de 368000 nuevos casos y un poco menos de 8900 nuevas muertes con una disminución del $17 \%$ y $21 \%$ respectivamente comparado con la semana anterior. Se ha presentado una fuerte tendencia a la baja de casos y muertes a lo largo de las últimas cuatro semanas. El mayor número de casos nuevos se notificó en la Federación Rusa (62 995 casos nuevos; incremento del $2 \%$ ), Francia (47 528 casos nuevos; disminución del 22\%) y Turquía (46 616 casos nuevos; disminución del $19 \%)$. El mayor número de nuevas muertes se registró en la Federación Rusa (2 625 nuevas muertes; similar a la semana anterior), Alemania (816 nuevas muertes; aumento del $20 \%$ ) y Turquía (797 nuevas muertes; disminución del 34\%)

Región de Asia Sudoriental. En la última semana, la región del Sudeste Asiático notificó cerca de 1 millón de nuevos casos y 23000 nuevas muertes, con una disminución del $31 \%$ y el $21 \%$ respectivamente en comparación con la semana anterior. La incidencia general de casos continúa disminuyendo (impulsado principalmente por las tendencias en India); sin embargo, se han observado aumentos notables en otras partes de la región. El mayor número de casos fue reportado por India (914 539 casos nuevos; disminución del 33\%), Indonesia (420 280 casos nuevos; similar a la semana anterior) y Nepal (31 678 casos nuevos; disminución del 34\%). El mayor número de nuevas muertes se registró en India (20 787 nuevas muertes; disminución del 22\%), Indonesia (1 187 nuevas muertes; un incremento del 12\%) y Nepal (636 nuevas muertes; una disminución del 37\%).

Región del Pacífico Occidental. La semana anterior se notificaron más de 138000 nuevos casos, similar a la semana anterior y poco más de 2400 nuevas muertes con un incremento del 19\% comparado con la semana anterior. El mayor número de casos nuevos se notificó en Malasia (52 040 casos nuevos; disminución del 3\%), Filipinas (45 681 casos nuevos; disminución del 19\%), y Japón (18 649 casos nuevos, una disminución del 32\%) El mayor número de nuevas muertes se registró en Filipinas (1 010 nuevas muertes; incremento de 30\%), Malasia (641 nuevas muertes; incremento del $42 \%$ ) y Japón (603 nuevas muertes; una disminución de 12\%).

Fuente: Organización Mundial de la Salud (OMS). Actualización epidemiológica semanal de COVID-19. Fecha de Publicación 08 de junio de 2021. Fecha de consulta 10 de junio de 2021. Disponible en: https:// www.who.int/publications/m/item/weekly-epidemiological-update-on-covid-19---8-june-2021

\section{Boletín de brotes y emergencias. Guinea, Brote Enfermedad Virus del Ébola (EVE) 31 de mayo - 06 junio de 2021, sema- na 23. Organización Mundial de la Salud (OMS)}

No se han confirmado nuevos casos de Enfermedad por Virus del Ébola (EVE) reportados por la provincia de N'Zerekore, sitio del actual brote de EVE en Guinea hasta el 6 de junio de 2021, a 13 días de la declaración de cierre del brote.

Al 6 de junio de 2021 se habían notificado un total de 23 casos, incluyendo 16 casos confirmados y 7 probables, de los cuales 9 se han recuperado y 12 han fallecido (tasa de letalidad del $52,2 \%$ ). El número de trabajadores de salud infectados siguen siendo cinco. Actualmente se encuentran hospitalizados cinco casos sospechosos. La mayoría de los casos confirmados y probables son mujeres (13/23: 60,9\%) y el grupo de edad más afectado es el de alrededor de los 40 años.

Actualmente no hay contactos activos en el seguimiento. Al 6 de junio de 2021 se recibieron un total de 62 nuevas alertas que han sido reportadas en N'Zerekore, incluidas nueve muertes, de las cuales 31 (50,0\%) fueron investigadas, 23 validadas, incluidas las nueve muertes. En las provincias vecinas se reportaron 20 alertas nuevas, todas fueron investigadas y ninguna validada. 
La cuenta regresiva de 42 días para el cierre del brote comenzó el 8 de mayo de 2021 con fecha prevista para la declaración del fin del brote es el 19 de junio de 2021, ubicándose ahora en el día 13. Se está proporcionando apoyo continuo a N'Zerekore y a todas las provincias vecinas que requieren fortalecimiento. El plan de resiliencia de 90 días requiere una revisión, que se está planificando. Todas las autoridades y socios deben continuar apoyando plenamente las operaciones de respuesta en esta etapa crítica del brote.

Se han vacunado a un total de 10873 personas, incluidos 622 contactos de alto riesgo, 9717 contactos de contactos y 534 contactos probables, incluidos 2879 trabajadores de primera línea. No se están administrando nuevas vacunas. Seis casos sospechosos fueron hospitalizados en los Centros para Enfermedades Epidémicas. Se notificaron 18 nuevas muertes en la comunidad, con nueve muestras recolectadas y sin entierros dignos y seguros realizados.

Las actividades de prevención y control de infecciones incluyeron la toma de hisopado a siete alertas de muertes en la comunidad. La comunicación del riesgo y participación comunitaria incluyo la investigación profunda sobre la experiencia de EVE en N'serekore; documentación de la contribución de la comunicación de riesgos, participación comunitaria y ciencias sociales por parte de la OMS y apoyo a la comisión de comunicación.

Fuente: Boletín de brotes y emergencias. Guinea, Brote Enfermedad Virus del Ébola (EVE) 31 de mayo - 06 junio de 2021, semana 23. Organización Mundial de la Salud (OMS). Fecha de publicación 06 de junio de 2021. Fecha de consulta 10 de junio de 2021. Disponible en: https://apps.who.int/iris/bitstream/handle/10665/341673/OEW23310506062021.pdf

\section{Infección humana por influenza aviar A (H10N3) - China.} Fecha de publicación 10 de junio de 2021. Organización mundial de la salud (OMS)

El 31 de mayo de 2021, la Comisión Nacional de Salud de la República Popular de China notificó a la OMS un caso confirmado de infección humana por el virus de la influenza aviar $A$ (H10N3). Este es el primer caso de infección humana por el virus de la influenza aviar $\mathrm{A}(\mathrm{H} 10 \mathrm{~N} 3)$ informado a nivel mundial. El caso hace referencia a un hombre de 41 años proveniente de la ciudad de Zhenjiang, provincia de Jiangsu, quien desarrolló fiebre y náuseas el 23 de abril de 2021, fue ingresado en la unidad de cuidados intensivos de un hospital local el 28 de abril de 2021. El caso se encuentra actualmente estable. El Centro Nacional de Influenza del Centro Chino para el Control y la Prevención de Enfermedades, un Centro Colaborador de la OMS de Referencia e Investigación sobre la Influenza, completó la secuenciación genética y el análisis de la muestra y confirmó la detección de un virus de influenza A (H1ON3) de origen aviar.

El caso no tenía antecedentes claros de exposición a aves de corral antes del inicio de la enfermedad, según la investigación epidemiológica. Así mismo, no se ha encontrado ningún virus de influenza aviar A (H10N3) en los alrededores locales o en aves de corral. Los contactos cercanos del caso no han mostrado ningún síntoma. Según la evaluación local y nacional, se consideró que el caso era una infección incidental de transmisión aviar a humana, con una baja probabilidad de transmisión de persona a persona.

La mayoría de las infecciones humanas por virus de la influenza aviar reportadas anteriormente se debieron a la exposi- 
ción a aves de corral infectadas o ambientes contaminados. Los virus de la influenza aviar, incluidos los virus $A(H 10 N x)$, continúan detectándose en las poblaciones de aves de corral y podrían detectarse casos esporádicos en humanos en el futuro. La información epidemiológica disponible actualmente siguiere que los virus $\mathrm{A}(\mathrm{H} 10 \mathrm{Nx})$ no han adquirido la capacidad de transmisión sostenida de persona a persona por lo que la probabilidad de propagación en humanos es baja.

Dentro de los consejos de la OMS, la detección de un caso no cambia las recomendaciones actuales sobre las medidas de salud pública y vigilancia de la influenza. Se recomienda evitar el contacto con entornos de alto riesgo, así como, la higiene de manos con lavado frecuente o del uso de desinfectantes de manos a base de alcohol. La OMS no recomienda ninguna medida específica para los viajeros y desaconseja la aplicación de restricciones de viaje o comerciales en relación con este evento basándose en la información actualmente disponible.

Fuente: Infección humana por influenza aviar A (H1ON3) - China. Organización mundial de la salud (OMS). Fecha de publicación 10 de junio de 2021. Fecha de consulta 10 de junio de 2021. Disponible en: https:// www.who.int/emergencies/disease-outbreak-news/item/human-infection-with-avian-influenza-a(h10n3)-china

Informe de amenazas de enfermedades transmisibles, 30 de mayo al 5 de junio de 2021. Semana 22. Centro Europeo para la Prevención y el Control de Enfermedades (ECDC)

Infección humana por la variante del virus de la influenza $\mathrm{A}(\mathrm{H} 1 \mathrm{~N} 2)$ en Estados Unidos. Fecha de publicación 4 de junio de 2021. Centro Europeo para la Prevención y el Control de Enfermedades (ECDC)
A finales de mayo de 2021, los CDC de EE.UU. informaron sobre un caso humano confirmado con infección por la variante $A(H 1 N 2)$ del virus (A(H1N2) v) en Ohio, EE.UU.

El paciente es un menor de 18 años, no requirió hospitalización y se recuperó de la enfermedad. No hay transmisión entre humanos de la influenza A(HIN2) asociadas a este caso. La investigación epidemiológica del caso revela que el paciente vive en una granja donde hay cerdos. Este es el primer caso reportado en Estados Unidos en lo corrido del año.

Los casos esporádicos de la infección de $\mathrm{A}(\mathrm{H} 1 \mathrm{~N} 2)$ v ocurren en los seres humanos que tienen contacto directo o indirecto con los cerdos y los ambientes contaminados. Desde 2005, se han reportado 29 casos de infección por A (H1N2)v en todo el mundo, de los cuales 27 se han presentado en los EE. UU. Se necesitan más investigaciones epidemiológicas, incluida la caracterización del virus, para evaluar la fuente de infección y el riesgo de transmisión a los seres humanos, así como entre los seres humanos. Se recomienda una estrecha cooperación intersectorial y comunicación entre las autoridades de sanidad animal y pública para comprender mejor los virus en circulación en los cerdos con el fin de aplicar medidas de seguridad y prevenir los eventos de transmisión zoonótica.

EI CDC está monitoreando eventos de influenza zoonótica a través de actividades de inteligencia epidemiológica con el fin de identificar cambios significativos en la epidemiología del virus.

Fuente: Informe de amenazas de enfermedades transmisibles, 30 de mayo al 5 de junio de 2021. Semana 22. Infección humana por la variante del virus de la influenza $A(H 1 N 2)$ en Estados Unidos. Centro Europeo para la Prevención y el Control de Enfermedades (ECDC). Fecha de publicación 4 de junio de 2021. Fecha de consulta 10 de junio de 2021. Disponible: https://www.ecdc.europa.eu/en/ publications-data/communicable-disease-threats-report-30-may5-june-2021-week-22 


\section{SITUACIÓN COVID-19}

Entre el 01 de enero de 2021 hasta el 10 de junio de 2021 se han confirmado por laboratorio 1853822 casos y 43128 muertes por COVID-19 en Colombia, en 38 entidades territoriales del orden departamental y distrital, afectando 1116 municipios. La incidencia 2021 (corte: 10 de junio) es de 3 688,34 casos por cada 100000 habitantes. A la fecha, el 8,1 $\%$ (150 573) de los casos se encuentra activos, procedente principalmente de Bogotá 49,3\% (74 183), Antioquia 15,2\% (22 832), Santander 5,5\% (8 223), Valle del Cauca 4,7\% (7 052) Cundinamarca 4,3\% (6 538), y Boyacá 1,8 \% (2 777). A nivel municipal (sin tener en cuenta distritos), el $16 \%$ de los casos activos se encuentra principalmente en Medellín - Antioquia 7,4 \% (11 150), Cali - Valle del Cauca 2,7 \% (4 043), Bucaramanga - Santander 2,4 \% (3 649), Bello - Antioquia 1,3 \% (1 968), Itagüí - Antioquia 1,1 \% (1 637) y Manizales Caldas 1,1\% (1 634).

La incidencia nacional de casos activos para el 2021 (corte: 10 de junio) es de 299,6 casos por 100000 habitantes. Los municipios con mayor incidencia de casos activos son: Bogotá (957,9), Segovia - Antioquia (789, 8), Capitanejo - Santander $(748,3)$, Guapotá - Santander (746,0), Toledo - Antioquia (713,9), Cácota - Norte de Santander (652,0), Rionegro Antioquia $(646,2)$, Tauramena - Casanare $(623,7)$ y Bucaramanga - Santander $(600,7)$. De los casos activos el 52,3\% (78 725 ) se presenta en mujeres y según grupo de edad el $74,4 \%$ (111966) se presenta en personas entre los 20 y los 59 años y el 13,6\% (20 508) en mayores de 60 años

Entre las semanas epidemiológicas (SE) 19 a 22 de 2021, a nivel nacional se notificaron 421075 casos de COVID-19 procedentes de 1085 municipios y 13088 muertes por CO-
VID-19 procedentes de 724 municipios. Durante este periodo se registró una incidencia de 891,68 casos por cada 100 000 habitantes, una tasa de mortalidad de 26,04 muertes por cada 100000 habitantes y una letalidad de 3,11\%. Adicionalmente, durante este periodo se observó una disminución no significativa en la incidencia de 0,9 y un incremento no significativo de la tasa de mortalidad de 1,1 y letalidad de 1,2 con respecto al periodo anterior (SE 18 - 21, 2021). Los departamentos y distritos que durante este periodo superaron la incidencia nacional $(891,38)$ por 100000 habitantes fueron Bogotá, D.C. (2 424,94), Archipiélago de San Andrés, Providencia y Santa Catalina (1 712,03), Cartagena $(1032,56)$, Casanare (1 000,89), Santander (987,82), Cundinamarca $(935,40)$, Boyacá $(915,36)$ y Antioquia $(909,16)$ (mapa 1).

Mapa 1. Mortalidad por COVID-19 por entidad territorial, Colombia, semana epidemiológica 19 a 22, 2021

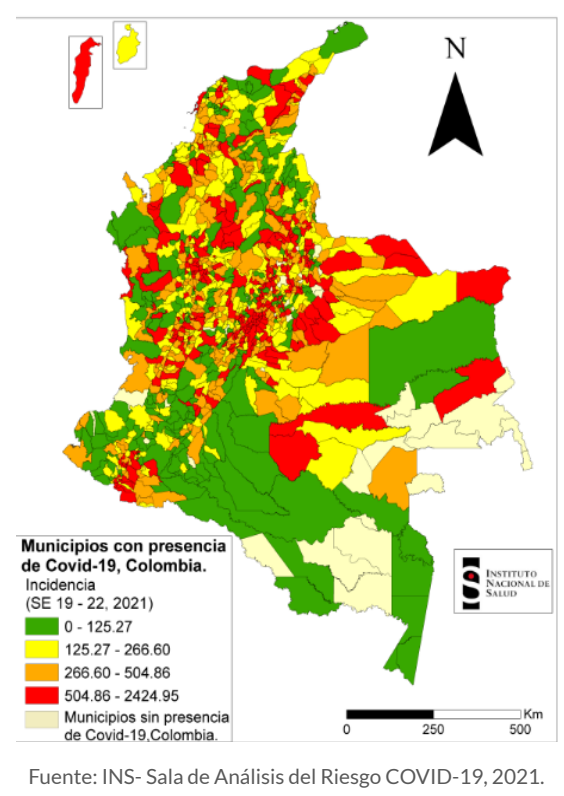

Tema central

Situación Nal.

Mortalidad

Trazadores

Brotes

COVID-19

Tablas 
Para este periodo comprendido entre las SE 19 a 22, 2021 se presentó un aumento significativo de la incidencia respecto al periodo anterior en las entidades territoriales de Vichada ( $\Delta$ $2,6)$, Caquetá $(\Delta 1,5)$, Huila $(\Delta 1,4)$, Arauca $(\Delta 1,4)$, Guaviare $(\Delta$ 1,4), Guainía ( $\Delta 1,3)$, Bogotá, D.C. $(\Delta 1,3)$, Nariño $(\Delta 1,2)$, Norte de Santander $(\Delta 1,2)$, Boyacá $(\Delta 1,1)$, Cundinamarca $(\Delta 1,1)$, Tolima $(\Delta 1,1)$, Buenaventura $(\Delta 1,1)$ y Santander $(\Delta 1,0)$. Por el contrario, las siguientes entidades territoriales registraron un descenso significativo en la incidencia de COVID-19 en comparación con el periodo anterior: Meta (1,0), Casanare (1,0), Sucre $(1,0)$, Valle del Cauca $(0,9)$, Cauca $(0,9)$, Bolívar $(0,9)$, Cali $(0,8)$, Caldas $(0,8)$, Risaralda $(0,8)$, Antioquia $(0,8)$, Córdoba $(0,7)$, Chocó (0,7), Cartagena (0,7), Archipiélago de San Andrés, Providencia y Santa Catalina $(0,7)$, Quindío $(0,6)$, Magdalena $(0,5)$, Santa Marta (0,5), Putumayo (0,5), Cesar $(0,5)$, Vaupés (0,4), Atlántico (0,3), Barranquilla (0,3), La Guajira $(0,3)$, Amazonas $(0,2)$

A nivel nacional, durante la SE 19 a 22, 2021 se registraron 6682 casos de COVID-19 en menores 5 años y se presentó 1 muerte por esta causa en este grupo de edad; la incidencia de COVID-19 para este periodo, en menores de 5 años fue de 172,22 casos por 100000 habitantes. En el grupo de 5 a 15 años, se registraron 21743 casos y 1 fallecido por COVID-19; en este grupo la incidencia COVID-19 de periodo fue de 253,19 casos por 100000 habitantes, la tasa de mortalidad de periodo fue de 0,01 casos por 100000 habitantes. En el grupo etario de 26 a 59 años durante la SE 19 a 22, 2021 se registraron a nivel nacional un total de 268931 casos y 4383 fallecidos por COVID-19, que corresponde al 33,5\% del total de muertes del periodo nacional. La incidencia de COVID-19 del periodo en este grupo fue de 1316,85 casos por cada por 100000 habitantes, la tasa de mortalidad de periodo fue de 19,59 casos por 100000 habitantes y la letalidad de periodo de 1,63\%. En el grupo etario de 60 a 69 años, se confirmaron durante este periodo 35115 casos y 3 831 fallecidos por COVID-19, que corresponde al 29,3\% del total de las muertes del periodo nacional; la incidencia COVID-19 de periodo en este grupo fue de 998,53 casos por 100000 habitantes, la tasa de mortalidad de periodo fue de 101,43 casos por 100000 habitantes y la letalidad de periodo de 10,91\%. En el grupo etario de 70 a 79 años, se registraron 13422 casos y 2 779 fallecidos por COVID-19, que corresponde al $21,2 \%$ del total de las muertes en este periodo (SE 19-22, 2021); la incidencia COVID-19 en este grupo fue de 720,51 casos por 100000 habitantes, la tasa de mortalidad fue de 140,18 casos por 100 000 habitantes y la letalidad de $20,7 \%$. En el grupo etario de 80 años y más se confirmaron durante este periodo (SE 19-22, 2021) 6808 casos y 2024 fallecidos por COVID-19, que corresponde al 15,5\% del total de las muertes del periodo nacional; la incidencia COVID-19 en este grupo fue de 732,31 casos por 100000 habitantes, la tasa de mortalidad fue de 204,82 casos por 100000 habitantes y la letalidad de $29,7 \%$.

Entre la SE 19 a 22, 2021 se notificaron 13088 muertes por COVID-19 procedentes de 724 municipios. Las entidades con mayor registro de fallecidos durante este periodo (SE 19 - 22, 2021) fueron: Bogotá D.C. con 24,1 \% (3 159), Antioquia con $13,5 \%$ (1 770), Cundinamarca con 7,6 \% (998), Santander con $7,1 \%$ (924), Valle del Cauca con 4,1 \% (535), Cali con 4,0\% (525) y Barranquilla con 4,0 \% (523).
Tema central

Situación Nal.

Mortalidad

Trazadores

Brotes

COVID-19

Tablas 
Entre las semanas epidemiológicas (SE) 19 a 22, 2021, los municipios y distritos con la mayor tasa de mortalidad por 100000 habitantes fueron: La Victoria - Valle del Cauca (101,5), Jerusalén - Cundinamarca (86,5), San Andrés - Archipiélago de San Andrés y Providencia (82,0), Contratación - Santander (81,5), Tópaga - Boyacá (81,4), Garagoa - Boyacá (71,1), Fusagasugá Cundinamarca (67,7), Bucaramanga - Santander (66,5), Calima - Valle del Cauca $(65,9)$ y Socorro - Santander $(65,6)$ (mapa 2).

Mapa 2. Mortalidad por COVID-19 por entidad territorial, Colombia, semana epidemiológica 19 a 22, 2021

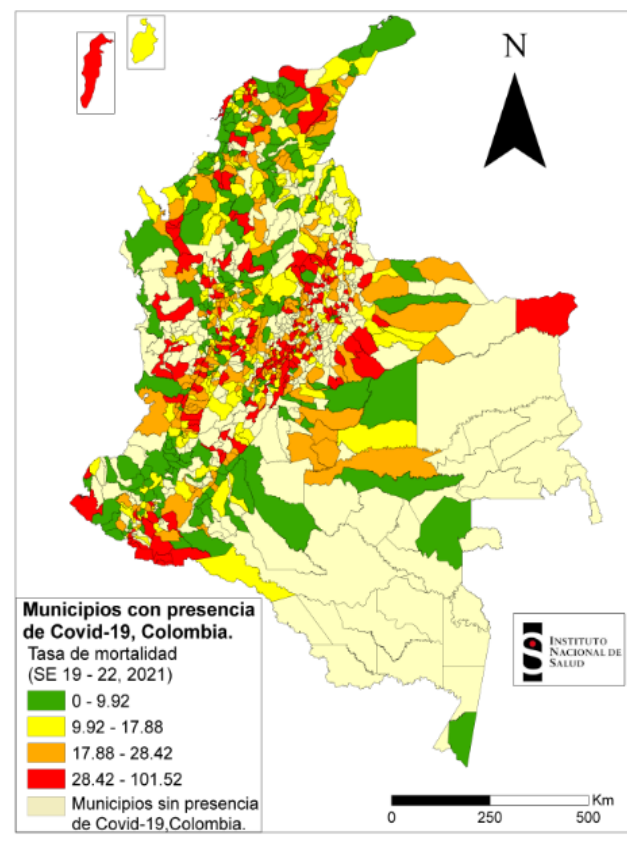

Fuente: INS- Sala de Análisis del Riesgo COVID19, 2021.
A nivel nacional, al comparar la tasa de mortalidad y letalidad de la SE 19 a 22, 2021 respecto al periodo anterior (SE 18 - 21, 2021), se observó que de los 724 municipios que reportaron muertes por $\mathrm{CO}$ VID-19 durante el periodo analizado, el 38,1 \% (276) presentó incremento significativo en ambos indicadores; de estos municipios los que presentaron mayor variación (aumento) en la tasa de mortalidad fueron Jerusalén - Cundinamarca $(\Delta 86,5)$, Contratación - Santander $(\Delta 81,5)$, Tópaga - Boyacá $(\Delta 81,4)$, Caldas - Boyacá $(\Delta 64,4)$, Floresta - Boyacá $(\Delta 62)$, Toledo - Antioquia $(\Delta 59,6)$, Nimaima - Cundinamarca $(\Delta 53,2)$; y los municipios que presentaron mayor variación (aumento) en la tasa de letalidad fueron Marulanda - Caldas ( $\Delta 100)$, Nariño - Cundinamarca ( $\Delta 100)$, Paicol - Huila $(\Delta 50)$, Francisco Pizarro - Nariño $(\Delta 50)$, Sáchica - Boyacá, Páez - Cauca, San Zenón - Magdalena, Charta - Santander y Valle de San Juan - Tolima con variación $(\Delta 33,3)$.

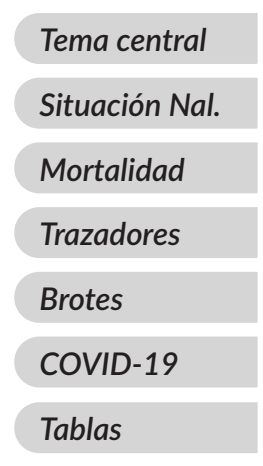




\section{TABLAS DE MANDO NACIONAL}

\begin{tabular}{|c|c|c|c|c|c|c|c|c|c|c|c|c|c|c|c|c|c|c|}
\hline \multirow[b]{2}{*}{ Departamento } & \multicolumn{3}{|c|}{ Accidente ofídico } & \multicolumn{3}{|c|}{$\begin{array}{c}\text { Agresiones por animales } \\
\text { potencialmente transmisores de } \\
\text { rabia } \\
\end{array}$} & \multicolumn{3}{|c|}{ Dengue } & \multicolumn{3}{|c|}{ EAPV } & \multicolumn{3}{|c|}{ Hepatitis A } & \multicolumn{3}{|c|}{ Intento de suicidio } \\
\hline & 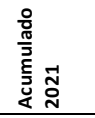 & 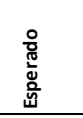 & 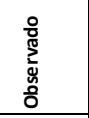 & 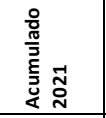 & 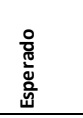 & 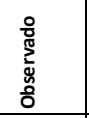 & 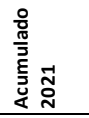 & 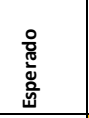 & $\begin{array}{l}\text { 웜 } \\
\text { 总 } \\
\text { o. } \\
\end{array}$ & 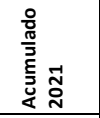 & 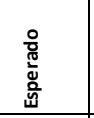 & 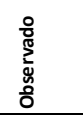 & 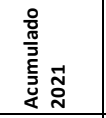 & 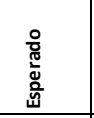 & 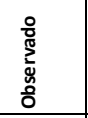 & 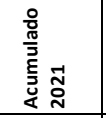 & $\begin{array}{l}\circ \\
\text { o. } \\
\frac{0}{0} \\
\frac{0}{4} \\
\end{array}$ & 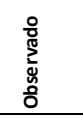 \\
\hline \begin{tabular}{|l|l|} 
Amazonas \\
\end{tabular} & 14 & 1 & 1 & 86 & 5 & 3 & 180 & 5 & 55 & 0 & 0 & 0 & 0 & 0 & 0 & 16 & 13 & 16 \\
\hline \begin{tabular}{|l|} 
Antioquia \\
\end{tabular} & 251 & 15 & 7 & 5.234 & 256 & 144 & 502 & 295 & 82 & 45 & 1 & 0 & 48 & 15 & 1 & 1.621 & 2.099 & 1.621 \\
\hline Arauca & 44 & 3 & 3 & 252 & 12 & 5 & 97 & 38 & 21 & 1 & 1 & 0 & 14 & 0 & 0 & \begin{tabular}{l|l}
63 \\
\end{tabular} & 91 & 63 \\
\hline Atlántico & 33 & 2 & 1 & 877 & 47 & 40 & 321 & 39 & 47 & 6 & 1 & 0 & 1 & 2 & 0 & 274 & 258 & 274 \\
\hline \begin{tabular}{|l|} 
Barranquilla \\
\end{tabular} & 4 & 1 & 0 & 728 & 40 & 23 & 380 & 34 & 26 & 2 & 1 & 0 & 5 & 2 & 0 & 294 & 320 & 294 \\
\hline \begin{tabular}{|l|} 
Bogotá \\
\end{tabular} & 0 & 0 & 0 & 6.886 & 356 & 244 & 0 & 0 & 0 & 270 & 4 & 1 & 7 & 8 & 0 & \begin{tabular}{l|l|}
1.607 \\
\end{tabular} & \begin{tabular}{l|l|}
1.187 \\
\end{tabular} & 1.607 \\
\hline Bolivar & 72 & 5 & 6 & 844 & 40 & 22 & 315 & 67 & 41 & 3 & 2 & 0 & 0 & 1 & 0 & 186 & 182 & 186 \\
\hline Boyacá & 37 & 1 & 0 & 1.697 & 101 & 64 & 172 & 57 & 37 & 22 & 0 & 1 & 3 & 1 & 0 & 264 & 297 & 264 \\
\hline \begin{tabular}{|l|} 
Buenaventura \\
\end{tabular} & 16 & 1 & 0 & 36 & 2 & 1 & 115 & \begin{tabular}{l|l}
9 \\
\end{tabular} & 12 & 0 & 0 & 0 & 0 & 0 & 0 & 34 & 25 & 34 \\
\hline \begin{tabular}{|l|} 
Caldas \\
\end{tabular} & 35 & 1 & 0 & 1.154 & 62 & 43 & 77 & 41 & 21 & 8 & 0 & 0 & 1 & 1 & 0 & 416 & 436 & 416 \\
\hline \begin{tabular}{|l|} 
Cali \\
\end{tabular} & 0 & 0 & 0 & 1.483 & 84 & 41 & 2.896 & 608 & 360 & 10 & 0 & 0 & 6 & 7 & 0 & 493 & 567 & 493 \\
\hline \begin{tabular}{|l|} 
Caquetá \\
\end{tabular} & 93 & 3 & 2 & 398 & 17 & 15 & 274 & 55 & 53 & 0 & 0 & 0 & 0 & 0 & 0 & 106 & 91 & 106 \\
\hline \begin{tabular}{|l|} 
Cartagena \\
\end{tabular} & 3 & 1 & 0 & 386 & 15 & 10 & 706 & 8 & 36 & 2 & 0 & 0 & 0 & 0 & 0 & 172 & 195 & 172 \\
\hline \begin{tabular}{|l|} 
Casanare \\
\end{tabular} & 59 & 5 & 5 & 408 & 24 & 10 & 282 & 113 & 97 & 4 & 0 & 0 & 8 & 0 & 0 & 131 & 112 & 131 \\
\hline \begin{tabular}{|l|} 
Cauca \\
\end{tabular} & 62 & 3 & 6 & 1.864 & 99 & 69 & 294 & 42 & 94 & 6 & 1 & 0 & 1 & 1 & 0 & 272 & 323 & 272 \\
\hline Cesar & 79 & 8 & 5 & 695 & 33 & 24 & 461 & 106 & 89 & 4 & 0 & 0 & 0 & 1 & 0 & 226 & 264 & 226 \\
\hline Chocó & 74 & 4 & 1 & 47 & 2 & 0 & 222 & 24 & 61 & 0 & 0 & 0 & 0 & 0 & 0 & 19 & 43 & 19 \\
\hline \begin{tabular}{|l|} 
Córdoba \\
\end{tabular} & 70 & 8 & 4 & $\begin{array}{ll}1.429 \\
\end{array}$ & 64 & 35 & 283 & \begin{tabular}{|l|}
88 \\
\end{tabular} & 73 & 10 & 0 & 0 & 0 & 1 & 0 & 330 & 332 & 330 \\
\hline \begin{tabular}{|l|} 
Cundinamarca \\
\end{tabular} & 35 & 2 & 1 & 4.047 & 187 & 134 & 470 & 233 & 96 & 19 & 1 & 0 & 2 & 4 & 0 & 630 & 699 & 630 \\
\hline \begin{tabular}{|l|} 
Guainía \\
\end{tabular} & 6 & 0 & 0 & 37 & 2 & 0 & 12 & 4 & 2 & 0 & 0 & 0 & 0 & 0 & 0 & 8 & 10 & 8 \\
\hline \begin{tabular}{|l|} 
Guaviare \\
\end{tabular} & 70 & 1 & 4 & 109 & 5 & 6 & 28 & 32 & 13 & 0 & 0 & 0 & 6 & 0 & 1 & 23 & 22 & 23 \\
\hline \begin{tabular}{|l|} 
Huila \\
\end{tabular} & 51 & 3 & 6 & 1.838 & 65 & 82 & 671 & 399 & 171 & 16 & 3 & 0 & 1 & 1 & 1 & 321 & 280 & 321 \\
\hline La Guajira & 15 & 2 & 0 & 545 & 28 & 18 & 41 & 35 & 6 & 1 & 0 & 0 & 0 & 0 & 0 & 78 & 103 & 78 \\
\hline \begin{tabular}{|l|} 
Magdalena \\
\end{tabular} & 46 & 3 & 4 & 736 & 40 & 32 & 289 & 32 & 65 & 8 & 0 & 0 & 0 & 1 & 0 & 121 & 101 & 121 \\
\hline \begin{tabular}{|l|} 
Meta \\
\end{tabular} & 112 & 7 & 2 & \begin{tabular}{ll|}
1.084 \\
\end{tabular} & 50 & 54 & 660 & 343 & 192 & 7 & 0 & 0 & 3 & 1 & 0 & 243 & 268 & 243 \\
\hline Nariño & 56 & 3 & 2 & 2.000 & 93 & 76 & 204 & 33 & 34 & 6 & 0 & 0 & 0 & 1 & 0 & 450 & 465 & 450 \\
\hline \begin{tabular}{|l} 
Norte de Santander \\
\end{tabular} & 157 & 6 & 11 & 1.240 & 70 & 52 & 635 & 160 & 177 & 9 & 1 & 0 & 25 & 13 & 0 & 386 & 319 & 386 \\
\hline \begin{tabular}{|l|} 
Putumayo \\
\end{tabular} & 58 & 2 & 3 & 463 & 19 & 20 & 773 & 88 & 149 & 2 & 0 & 0 & 0 & 0 & 0 & 122 & 128 & 122 \\
\hline \begin{tabular}{|l|} 
Quindío \\
\end{tabular} & 10 & 0 & 0 & 769 & 48 & 28 & 83 & 64 & 24 & 6 & 0 & 0 & 1 & 2 & 0 & 259 & 221 & 259 \\
\hline \begin{tabular}{|l|} 
Risaralda \\
\end{tabular} & 21 & 1 & 1 & $\begin{array}{ll}1.275 \\
\end{array}$ & 57 & 45 & 83 & 30 & 20 & 2 & 1 & 0 & 2 & 1 & 0 & 373 & 424 & 373 \\
\hline San Andrés & 0 & 0 & 0 & 51 & 6 & 2 & 32 & 2 & 1 & 0 & 0 & 0 & 0 & 0 & 0 & 1 & 4 & 1 \\
\hline Santa Marta D.E. & 8 & 1 & 1 & 392 & 32 & 15 & 178 & 11 & 20 & 6 & 0 & 0 & 0 & 0 & 0 & 92 & 103 & 92 \\
\hline Santander & 76 & 3 & 5 & 1.841 & 85 & 57 & 420 & 530 & 94 & 9 & 2 & 0 & 3 & 6 & 0 & 492 & 424 & 492 \\
\hline \begin{tabular}{|l|} 
Sucre \\
\end{tabular} & 23 & 3 & 0 & 792 & 42 & 18 & 258 & 84 & 42 & 7 & 1 & 0 & 1 & 1 & 0 & 139 & 173 & 139 \\
\hline Tolima & 59 & 2 & 1 & \begin{tabular}{ll|l}
1.788 \\
\end{tabular} & 84 & 76 & 742 & 411 & 201 & 29 & 1 & 1 & 3 & 2 & 0 & 477 & 500 & 477 \\
\hline Valle del Cauca & 27 & 1 & 1 & $\begin{array}{ll}2.219 \\
\end{array}$ & 116 & 70 & 1.316 & 253 & 242 & 10 & 1 & 0 & 1 & 2 & 0 & 444 & 532 & 444 \\
\hline \begin{tabular}{|l|} 
Vaupés \\
\end{tabular} & 24 & 1 & 3 & 65 & 3 & 3 & 2 & 0 & 1 & 1 & 0 & 0 & 0 & 0 & 0 & 7 & $\begin{array}{ll}11 \\
\end{array}$ & 7 \\
\hline Vichada & 16 & 1 & 1 & 96 & 3 & 4 & 18 & 19 & 5 & 0 & 0 & 0 & 0 & 0 & 0 & 2 & 9 & 2 \\
\hline \begin{tabular}{|l} 
Total nacional \\
\end{tabular} & $\begin{array}{lll}1.816 \\
\end{array}$ & 101 & 87 & \begin{tabular}{|l|}
45.891 \\
\end{tabular} & 2.292 & 1.585 & 14.492 & $\begin{array}{ll}4.392 \\
\end{array}$ & 2.760 & 531 & 21 & 3 & 142 & 71 & 3 & \begin{tabular}{ll|}
11.192 \\
\end{tabular} & \begin{tabular}{l|}
11.631 \\
\end{tabular} & 11.192 \\
\hline
\end{tabular}

Tema central

Situación Nal.

Mortalidad

Trazadores

Brotes

COVID-19

Tablas

2 instituto 


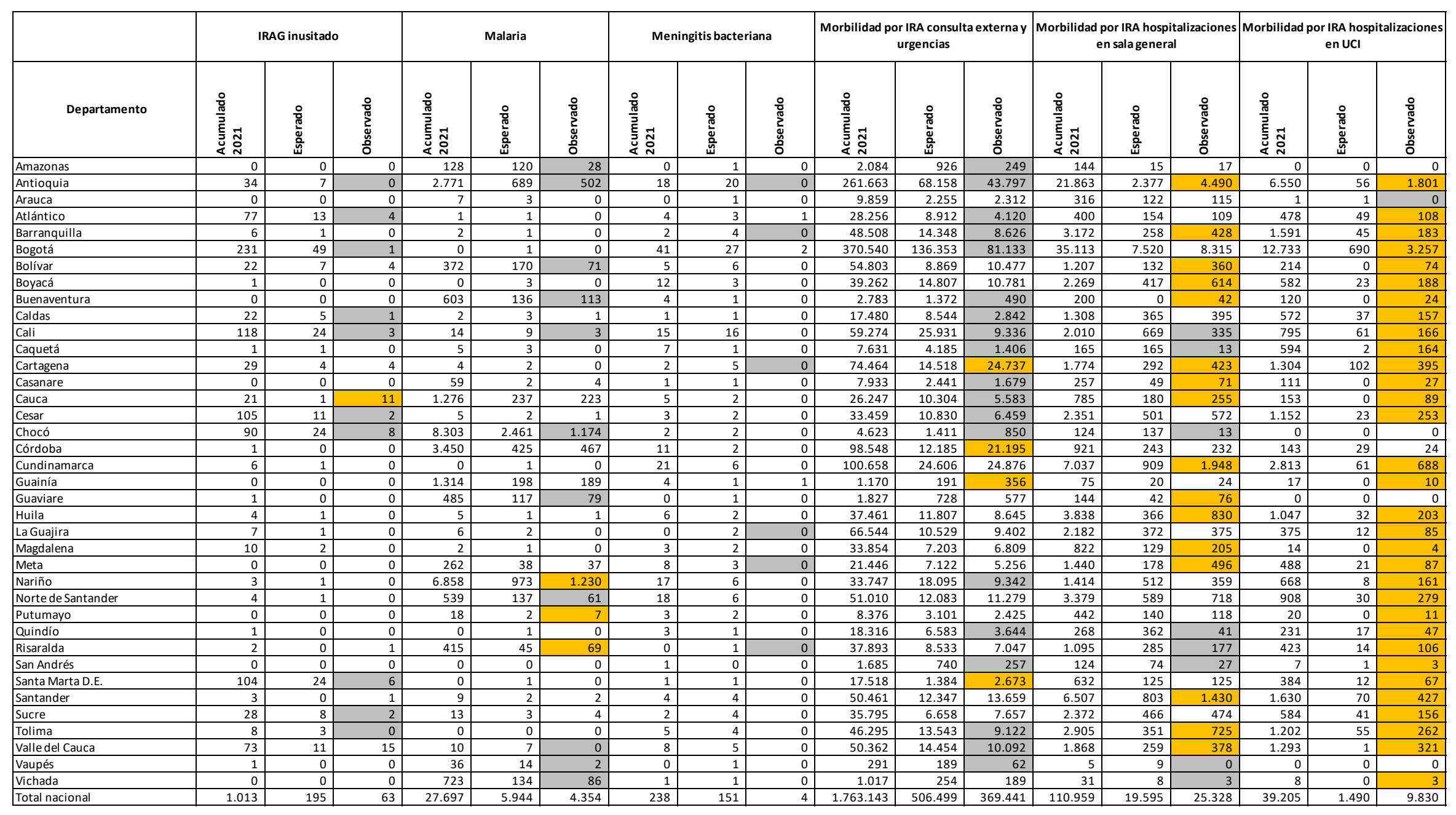




\begin{tabular}{|c|c|c|c|c|c|c|c|c|c|c|c|c|c|c|c|c|c|c|c|c|c|}
\hline \multirow[b]{2}{*}{ Departamento } & \multicolumn{3}{|c|}{ Morbilidad por EDA } & \multicolumn{3}{|c|}{$\begin{array}{l}\text { Mortalidad perinatal y neonatal } \\
\text { tardía }\end{array}$} & \multicolumn{3}{|c|}{ Parálisis flácida aguda } & \multicolumn{3}{|c|}{ Parotiditis } & \multicolumn{3}{|c|}{ Sindrome de rubeola congénita } & \multicolumn{3}{|c|}{ Tos ferina } & \multicolumn{3}{|c|}{ Varicela } \\
\hline & 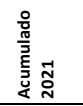 & 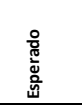 & 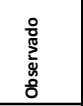 & 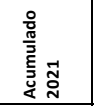 & 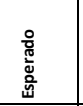 & 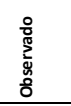 & 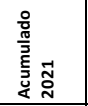 & 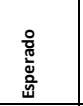 & 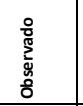 & 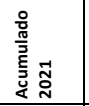 & 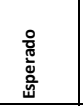 & 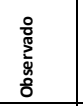 & 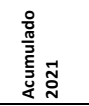 & 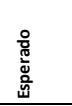 & 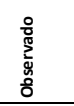 & 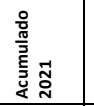 & 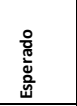 & 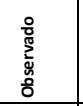 & 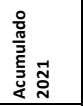 & 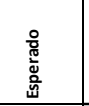 & 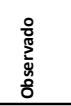 \\
\hline \begin{tabular}{|l|} 
Amazonas \\
Mtizis
\end{tabular} & 1.548 & 446 & 246 & 6 & 3 & 1 & 0 & 0 & 0 & 1 & 0 & 0 & 2 & 0 & 0 & 0 & 0 & 0 & 5 & 16 & 1 \\
\hline Antioquia & 134.319 & $\begin{array}{l}33.694 \\
\end{array}$ & $\begin{array}{l}18.913 \\
512\end{array}$ & 415 & 85 & 74 & 1 & 6 & 0 & 165 & 67 & 27 & 26 & 3 & 1 & 71 & 57 & 9 & 364 & 704 & 43 \\
\hline 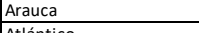 & 2.909 & 773 & 512 & 38 & 4 & 5 & 1 & 0 & 0 & 6 & 2 & 1 & 4 & 0 & 0 & 0 & 4 & 0 & 15 & 51 & 3 \\
\hline Atlántico & 8.891 & 4.670 & 1.709 & 109 & 20 & 20 & 0 & 2 & 0 & 13 & 13 & 1 & 0 & 1 & 0 & 2 & 1 & 0 & 79 & 251 & 12 \\
\hline Barranquilla & 14.515 & 6.633 & 2.254 & 171 & 29 & 19 & 0 & 1 & 0 & 20 & 21 & 3 & 0 & 1 & 0 & 0 & 1 & 0 & 56 & 311 & 10 \\
\hline Bogotá & 174.739 & 57.860 & 25.728 & 345 & 105 & 70 & 3 & 6 & 0 & 340 & 313 & 49 & 123 & 4 & 7 & 141 & 187 & 29 & 696 & 1.964 & 103 \\
\hline Bolivar & 10.347 & 3.228 & 2.153 & 115 & 21 & 16 & 1 & 1 & 0 & 5 & 6 & 0 & 0 & 1 & 0 & 10 & 2 & 0 & 61 & 142 & 16 \\
\hline Boyacá & 10.963 & 4.818 & 1.569 & 74 & 15 & 18 & 4 & 1 & 0 & 24 & 27 & 6 & 3 & 1 & 0 & \begin{tabular}{l|l}
3 \\
\end{tabular} & 10 & 2 & 89 & 159 & \\
\hline Buenaventura & 669 & 663 & 95 & 29 & 7 & 3 & 0 & 0 & 0 & 1 & 0 & 0 & 0 & 0 & 0 & \begin{tabular}{l|l}
0 \\
\end{tabular} & 0 & 0 & 7 & 12 & 0 \\
\hline Caldas & 7.346 & 3.375 & 1.049 & 44 & 10 & 8 & 1 & 1 & 0 & 16 & 10 & 3 & 2 & 0 & 0 & 2 & 7 & 0 & 47 & 109 & 8 \\
\hline Cali & 36.155 & 13.956 & 4.095 & 130 & 30 & 24 & 4 & 2 & 0 & 55 & 26 & 7 & 0 & 1 & 0 & 11 & 11 & 0 & 201 & 334 & 13 \\
\hline Caquetá & 4.286 & 1.766 & 676 & 32 & 7 & 3 & 1 & 1 & 0 & 12 & 4 & 1 & 2 & 0 & 0 & \begin{tabular}{l|l}
9 \\
\end{tabular} & 6 & 0 & 57 & 37 & 15 \\
\hline Cartagena & 15.326 & 4.682 & 1.617 & 93 & 22 & 14 & 0 & 1 & 0 & 8 & 3 & 2 & 0 & 1 & 0 & \begin{tabular}{l|l}
3 \\
\end{tabular} & 2 & 1 & 51 & 164 & 1 \\
\hline \begin{tabular}{|l|l} 
Casanare \\
\end{tabular} & 3.588 & 1.258 & 695 & 38 & 7 & 4 & 1 & 1 & 0 & 10 & 3 & 1 & 11 & 0 & 0 & \begin{tabular}{l|l}
0 \\
\end{tabular} & 3 & 0 & 31 & 39 & 2 \\
\hline Cauca & 14.894 & 4.721 & 3.504 & \begin{tabular}{l|l|l}
127 \\
\end{tabular} & 24 & 21 & 1 & 2 & 0 & 29 & 10 & 1 & 0 & 1 & 0 & 11 & 4 & 2 & 50 & 84 & 4 \\
\hline Cesar & 14.644 & 5.258 & 3.325 & 118 & 28 & 23 & 0 & 2 & 0 & 10 & 4 & 1 & 0 & 1 & 0 & \begin{tabular}{l|l}
4 \\
\end{tabular} & 4 & 2 & 40 & 82 & 5 \\
\hline Chocó & 1.879 & 850 & 428 & \begin{tabular}{l|l}
63 \\
\end{tabular} & 16 & 11 & 0 & 1 & 0 & 1 & 1 & 0 & 0 & 0 & 0 & \begin{tabular}{l|l}
1 \\
\end{tabular} & 2 & 1 & 3 & 7 & 0 \\
\hline Córdoba & 13.118 & 5.198 & 2.281 & 192 & 38 & 25 & 1 & 2 & 0 & 36 & 27 & 5 & 0 & 1 & 0 & \begin{tabular}{l|l}
4 \\
\end{tabular} & 2 & 2 & 109 & 304 & 10 \\
\hline \begin{tabular}{|l|} 
Cundinamarca \\
\end{tabular} & $\begin{array}{l}39.837 \\
\end{array}$ & $\begin{array}{ll}11.296 \\
\end{array}$ & 5.626 & 204 & 42 & 37 & 4 & 3 & 0 & 83 & 48 & 8 & 38 & 1 & 0 & 37 & 36 & 8 & 273 & 435 & 35 \\
\hline Guainía & 720 & 146 & 127 & 13 & 1 & 1 & 0 & 0 & 0 & 1 & 0 & 0 & \begin{tabular}{c|}
4 \\
\end{tabular} & 0 & 0 & \begin{tabular}{l|l}
0 \\
\end{tabular} & 0 & 0 & 2 & 5 & 0 \\
\hline Guaviare & 1.238 & 351 & 175 & \begin{tabular}{l|l}
9 \\
\end{tabular} & 1 & 1 & 1 & 0 & 0 & 2 & 0 & 0 & 0 & 0 & 0 & \begin{tabular}{l|l}
0 \\
\end{tabular} & 0 & 0 & 22 & 8 & 0 \\
\hline Huila & 15.026 & $\begin{array}{ll}4.147 \\
\end{array}$ & 2.187 & 75 & 19 & 12 & 4 & 1 & 0 & 34 & 13 & 4 & 3 & 1 & 0 & 15 & 15 & 4 & 77 & 120 & 8 \\
\hline \begin{tabular}{|l} 
La Guajira \\
\end{tabular} & 12.829 & 4.350 & 2.155 & 137 & 29 & 21 & 0 & 1 & 0 & 3 & 3 & 1 & 0 & 1 & 0 & 0 & 1 & 0 & 26 & 78 & 6 \\
\hline Magdalena & 13.084 & 4.100 & 2.572 & 78 & 18 & 11 & 0 & 1 & 0 & 2 & 4 & 0 & 0 & 1 & 0 & 1 & 1 & 0 & 36 & 69 & 6 \\
\hline Meta & 12.632 & 4.930 & 2.266 & 65 & 17 & 13 & 2 & 1 & 0 & 21 & 99 & 3 & 2 & 1 & 0 & 7 & 8 & 2 & 68 & 159 & 7 \\
\hline Nariño & 20.154 & 7.931 & 3.111 & 94 & 23 & 16 & 4 & 2 & 0 & 30 & 10 & 1 & \begin{tabular}{c|}
4 \\
\end{tabular} & 1 & 0 & 27 & 15 & 7 & 92 & 239 & 7 \\
\hline Norte de Santander & 21.206 & 5.722 & 3.771 & 108 & 22 & 21 & 2 & 2 & 0 & 40 & 26 & 4 & 2 & 1 & 0 & 33 & 13 & 12 & 183 & 290 & 23 \\
\hline \begin{tabular}{|l|} 
Putumayo \\
\end{tabular} & 2.987 & 1.119 & 391 & 27 & \begin{tabular}{c|c}
6 \\
\end{tabular} & 1 & 0 & 0 & 0 & 11 & 4 & 2 & 2 & 0 & 0 & \begin{tabular}{l|l}
6 \\
\end{tabular} & 2 & 0 & 32 & 28 & 6 \\
\hline Quindio & 9.915 & 2.652 & 1.864 & 33 & 6 & 9 & 0 & 0 & 0 & 10 & 3 & 3 & 2 & 0 & 0 & 0 & 1 & 0 & 62 & 76 & 8 \\
\hline \begin{tabular}{|l|} 
Risaralda \\
\end{tabular} & 18.487 & 4.221 & 3.395 & 55 & 10 & 7 & 1 & 1 & 0 & 13 & 5 & 5 & 1 & 0 & 0 & 3 & 3 & 0 & 74 & 89 & 8 \\
\hline San Andrés & 546 & 278 & 85 & 5 & 1 & 1 & 0 & 0 & 0 & 2 & 1 & 1 & 0 & 0 & 0 & 0 & 0 & 0 & 9 & 8 & 2 \\
\hline \begin{tabular}{|l} 
Santa Marta D.E. \\
\end{tabular} & 4.566 & 869 & 944 & 40 & 11 & 4 & 0 & 1 & 0 & 1 & 3 & 1 & 0 & 0 & 0 & 0 & 1 & 0 & 11 & 61 & 2 \\
\hline \begin{tabular}{|l|} 
Santander \\
\end{tabular} & 22.388 & 7.305 & 3.537 & 101 & 24 & 16 & 0 & 2 & 0 & 14 & 14 & 5 & 0 & 1 & 0 & 25 & 21 & 3 & 100 & 267 & 13 \\
\hline Sucre & 6.621 & 3.035 & 1.274 & 99 & 17 & 16 & 1 & 1 & 0 & 13 & 16 & 1 & 0 & 1 & 0 & 24 & 12 & 3 & 41 & 174 & 7 \\
\hline Tolima & 42.799 & 5.650 & 7.996 & 79 & 21 & 14 & 1 & 1 & 0 & $\begin{array}{ll}19 \\
\end{array}$ & 11 & 2 & 7 & 1 & 0 & 12 & 11 & 5 & 95 & 184 & 12 \\
\hline Valle del Cauca & 17.177 & 7.353 & 2.247 & 100 & 21 & 26 & 0 & 2 & 0 & 28 & 13 & 2 & 1 & 1 & 0 & \begin{tabular}{c|c}
9 \\
\end{tabular} & 3 & 2 & 169 & 253 & 19 \\
\hline \begin{tabular}{|l} 
Vaupés \\
\end{tabular} & 192 & 84 & 32 & 7 & 1 & 3 & 0 & 0 & 0 & 1 & 0 & 1 & 0 & 0 & 0 & 0 & 1 & 0 & 0 & 5 & 0 \\
\hline Vichada & 609 & 204 & 122 & 11 & 3 & 0 & 0 & 0 & 0 & 1 & 0 & 0 & 1 & 0 & 0 & 0 & 4 & 0 & 9 & 6 & 0 \\
\hline \begin{tabular}{|l|} 
Total nacional \\
\end{tabular} & 733.149 & 229.592 & \begin{tabular}{ll|l|}
114.726 \\
\end{tabular} & 3.479 & \begin{tabular}{|l|l|}
763 \\
\end{tabular} & 589 & 39 & 50 & 0 & \begin{tabular}{l|l|}
1.081 \\
\end{tabular} & 720 & \begin{tabular}{l|l}
152 \\
\end{tabular} & 240 & 27 & 8 & \begin{tabular}{l|l}
471 \\
471
\end{tabular} & 451 & 94 & 3.342 & 7.324 & 422 \\
\hline
\end{tabular}

\section{Tema central}

Situación Nal.

Mortalidad

Trazadores

Brotes

COVID-19

Tablas 


\section{Comportamiento de la notificación por departamento a semana 22}

Decremento

Incremento

\begin{tabular}{|c|c|c|c|c|c|c|c|c|c|c|c|c|c|c|c|c|}
\hline \multirow[b]{2}{*}{ Departamento } & \multicolumn{2}{|c|}{ Chagas agudo } & \multicolumn{2}{|c|}{ Chikungunya } & \multicolumn{2}{|c|}{ Difteria } & \multicolumn{2}{|c|}{$\begin{array}{c}\text { Enfermedad por virus } \\
\text { Zika }\end{array}$} & \multicolumn{2}{|c|}{ Leishmaniasis } & \multicolumn{2}{|c|}{ Leptospirosis } & \multicolumn{2}{|c|}{ Mortalidad materna } & \multicolumn{2}{|c|}{$\begin{array}{l}\text { Mortalidad por IRA en } \\
\text { menores de } 5 \text { años }\end{array}$} \\
\hline & 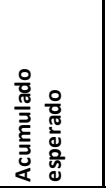 & 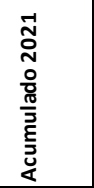 & & 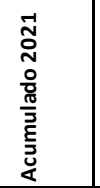 & $\begin{array}{l}\frac{0}{0} \\
\frac{\pi}{3} \\
\frac{\pi}{5} \\
\frac{\pi}{2} \\
\overline{0} \\
\frac{0}{4}\end{array}$ & 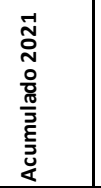 & 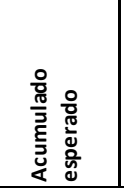 & 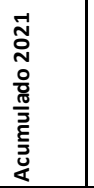 & 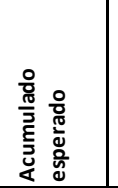 & 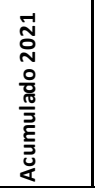 & 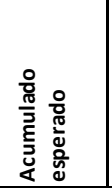 & 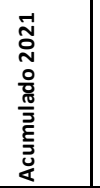 & 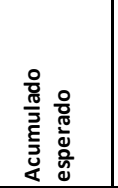 & 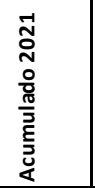 & 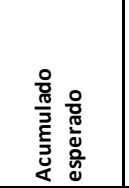 & 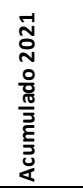 \\
\hline \begin{tabular}{|l|} 
Amazonas \\
\end{tabular} & 0 & 0 & 3 & 0 & 0 & 0 & 0 & 0 & \begin{tabular}{l|l}
5 \\
\end{tabular} & 5 & 0 & 4 & 1 & 0 & 1 & 2 \\
\hline \begin{tabular}{|l|} 
Antioquia \\
\end{tabular} & 1 & 0 & 19 & 4 & 1 & 0 & 4 & 3 & 687 & 374 & 116 & 145 & 10 & 22 & 31 & 12 \\
\hline \begin{tabular}{|l|} 
Arauca \\
\end{tabular} & 1 & 6 & 3 & 0 & 0 & 0 & 3 & 0 & 7 & 9 & 1 & 1 & 1 & 1 & 0 & 2 \\
\hline Atlántico & 1 & 0 & 8 & 0 & 0 & 0 & 3 & 3 & 1 & 1 & 17 & 18 & 5 & 6 & 3 & 3 \\
\hline \begin{tabular}{|l|} 
Barranquilla \\
\end{tabular} & 0 & 0 & 8 & 0 & 0 & 0 & 3 & 7 & 1 & 1 & 18 & 20 & 4 & 7 & \begin{tabular}{l|l}
3 \\
\end{tabular} & 4 \\
\hline \begin{tabular}{|l|} 
Bogotá \\
\end{tabular} & 1 & 0 & 0 & 0 & 1 & 0 & 3 & 9 & 0 & 0 & 16 & 40 & 11 & 18 & 28 & 12 \\
\hline Bolívar & 0 & 0 & 2 & 0 & 0 & 0 & 2 & 0 & \begin{tabular}{|c|}
177 \\
\end{tabular} & 124 & 16 & 11 & 3 & 6 & 8 & 7 \\
\hline Boyacá & 2 & 1 & 2 & 0 & 0 & 0 & 3 & 0 & 60 & 38 & 2 & \begin{tabular}{l|l}
4 & -1
\end{tabular} & 3 & 1 & \begin{tabular}{l|l}
3 \\
\end{tabular} & 0 \\
\hline Buenaventura & 0 & 0 & 1 & 0 & 0 & 0 & 0 & 0 & 15 & 3 & 15 & 33 & 1 & 2 & 1 & 0 \\
\hline \begin{tabular}{|l|} 
Caldas \\
\end{tabular} & 0 & 0 & 3 & 0 & 0 & 0 & 0 & 0 & 74 & 120 & 6 & 13 & 1 & 2 & 3 & 2 \\
\hline Cali & 0 & 0 & 42 & 0 & 0 & 0 & 29 & 3 & \begin{tabular}{l|l}
3 & \\
\end{tabular} & 1 & 45 & \begin{tabular}{l|l}
69 \\
\end{tabular} & 4 & 8 & 6 & 0 \\
\hline Caquetá & 0 & 1 & 7 & 0 & 0 & 0 & 3 & 0 & 124 & 92 & 5 & 6 & 2 & 0 & 2 & 2 \\
\hline \begin{tabular}{|l|} 
Cartagena \\
\end{tabular} & 0 & 0 & 6 & 0 & 0 & 0 & 1 & 0 & 0 & 1 & 5 & 16 & 4 & 2 & 6 & 1 \\
\hline Casanare & 8 & 1 & 11 & 0 & 0 & 0 & 2 & 2 & \begin{tabular}{l|l}
6 \\
\end{tabular} & 4 & 4 & 7 & 1 & 4 & 1 & 1 \\
\hline Cauca & 0 & 0 & 2 & 0 & 0 & 0 & 1 & 0 & \begin{tabular}{l|l|}
47 \\
\end{tabular} & 16 & 21 & 23 & 4 & 0 & 3 & 2 \\
\hline \begin{tabular}{|l|} 
Cesar \\
\end{tabular} & 0 & 0 & 3 & 0 & 0 & 0 & 2 & 1 & 20 & 17 & 10 & 18 & 6 & 8 & 8 & 10 \\
\hline Chocó & 0 & 0 & 1 & 0 & 0 & 0 & 0 & 0 & 145 & 121 & 13 & 11 & 7 & 5 & \begin{tabular}{l|l|}
16 \\
\end{tabular} & 17 \\
\hline \begin{tabular}{|l|} 
Córdoba \\
\end{tabular} & 1 & 0 & 3 & 0 & 0 & 0 & 3 & 2 & 61 & 51 & 5 & 18 & 5 & 7 & 5 & 3 \\
\hline Cundinamarca & 1 & 0 & 31 & 3 & 0 & 0 & 14 & 11 & 105 & 47 & 22 & 25 & 7 & 9 & 10 & 3 \\
\hline \begin{tabular}{|l|} 
Guainía \\
\end{tabular} & 0 & 0 & 0 & 0 & 0 & 0 & 0 & 1 & 22 & 1 & 7 & 0 & 0 & 0 & 0 & 2 \\
\hline \begin{tabular}{|l|} 
Guaviare \\
\end{tabular} & 0 & 0 & 13 & 0 & 0 & 0 & 2 & 0 & \begin{tabular}{l|l|}
156 \\
\end{tabular} & 147 & 4 & 10 & 0 & 1 & 0 & 0 \\
\hline \begin{tabular}{|l|} 
Huila \\
\end{tabular} & 0 & 0 & 20 & 0 & 0 & 0 & 4 & 1 & 20 & 4 & 35 & 35 & 1 & 3 & \begin{tabular}{l|l}
3 \\
\end{tabular} & 5 \\
\hline \begin{tabular}{|l|} 
La Guajira \\
\end{tabular} & 0 & 0 & 1 & 0 & 0 & 0 & 0 & 0 & 28 & 15 & 0 & 1 & 11 & 11 & 16 & 12 \\
\hline \begin{tabular}{|l|} 
Magdalena \\
\end{tabular} & 0 & 0 & 1 & 0 & 0 & 0 & 0 & 1 & $3 \mid$ & 1 & 1 & 1 & 6 & 14 & 7 & 4 \\
\hline Meta & 1 & 0 & 19 & 1 & 0 & 0 & 5 & 3 & 169 & 87 & 4 & 11 & 3 & 7 & 3 & 2 \\
\hline \begin{tabular}{|l|} 
Nariño \\
\end{tabular} & 0 & 0 & 0 & 0 & 0 & 0 & 1 & 2 & 283 & 130 & 3 & 10 & 8 & 7 & 5 & 3 \\
\hline $\mid$\begin{tabular}{|l|} 
Norte de Santander \\
\end{tabular} & 1 & 0 & 10 & 0 & 1 & 0 & 33 & 1 & 252 & 104 & 8 & 2 & 5 & 7 & 4 & 4 \\
\hline \begin{tabular}{|l|} 
Putumayo \\
\end{tabular} & 0 & 0 & 30 & 3 & 0 & 0 & 43 & 0 & 88 & 70 & 5 & 7 & 2 & 2 & 2 & 1 \\
\hline Quindío & 0 & 0 & 4 & 0 & 0 & 0 & 1 & 1 & 1 & 2 & 22 & 39 & 0 & 2 & 3 & 0 \\
\hline Risaralda & 0 & 0 & 16 & 0 & 0 & 0 & 5 & 1 & 124 & 27 & 74 & 69 & 2 & 5 & 3 & 6 \\
\hline San Andrés & 0 & 0 & 1 & 0 & 0 & 0 & 0 & 0 & \begin{tabular}{l|l}
0 \\
\end{tabular} & 0 & 0 & 0 & 0 & 0 & 0 & 0 \\
\hline Santa Marta D.E. & 0 & 0 & 3 & 0 & 0 & 0 & 1 & 0 & 7 & 2 & 0 & 3 & 2 & 8 & 1 & 3 \\
\hline \begin{tabular}{|l} 
Santander \\
\end{tabular} & 3 & 0 & 38 & 1 & 0 & 0 & 17 & 2 & 333 & 244 & 16 & 19 & 3 & 6 & 3 & 7 \\
\hline Sucre & 1 & 0 & 2 & 0 & 0 & 0 & 1 & 0 & 28 & 36 & 19 & 15 & 2 & 3 & 6 & 2 \\
\hline \begin{tabular}{|l|} 
Tolima \\
\end{tabular} & 2 & 0 & 40 & 1 & 0 & 0 & 16 & 4 & 558 & 84 & 91 & 87 & 4 & 2 & \begin{tabular}{l|l}
6 \\
\end{tabular} & 4 \\
\hline Valle del Cauca & 0 & 0 & 10 & 2 & 0 & 0 & 40 & 0 & 19 & 3 & 141 & 68 & 3 & 5 & 4 & 8 \\
\hline Vaupés & 0 & 0 & 0 & 0 & 0 & 0 & 0 & 0 & 23 & 14 & 0 & 16 & 0 & 0 & 1 & 0 \\
\hline \begin{tabular}{|l|} 
Vichada \\
\end{tabular} & 0 & 0 & 0 & 0 & 0 & 0 & 2 & 0 & 20 & 13 & 1 & 0 & 2 & 1 & 4 & 0 \\
\hline \begin{tabular}{|l|} 
Total nacional \\
\end{tabular} & 24 & 9 & 363 & 15 & 3 & 0 & 247 & 58 & \begin{tabular}{l|}
3.672 \\
\end{tabular} & 2.009 & 768 & 875 & 134 & 192 & 209 & 146 \\
\hline
\end{tabular}

Tema central

Situación Nal.

Mortalidad

Trazadores

Brotes

COVID-19

Tablas

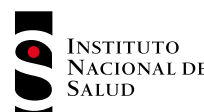




\section{Semana epidemiológica 22}

30 de mayo al 5 de junio de 2021

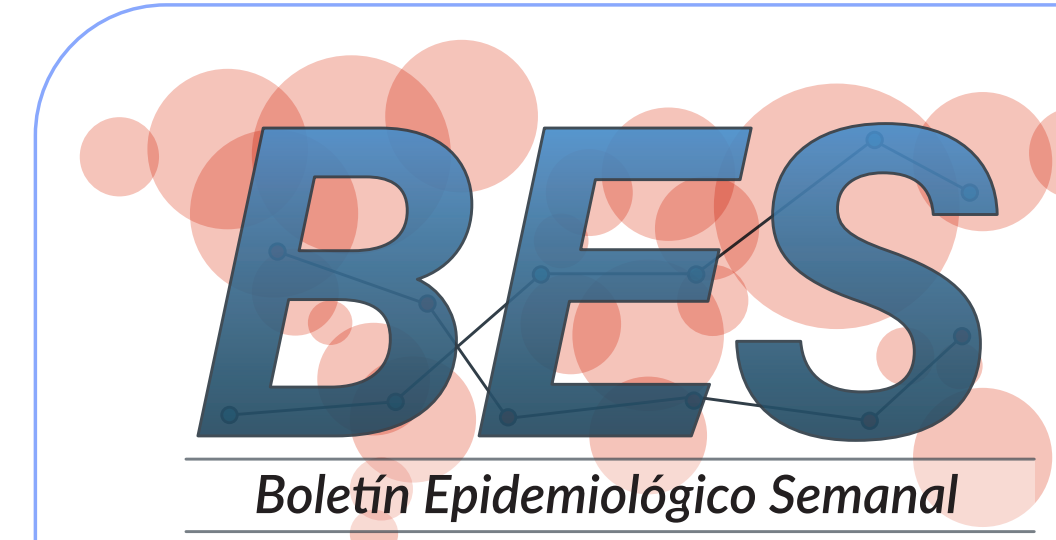

\section{Boletín Epidemiológico Semanal}

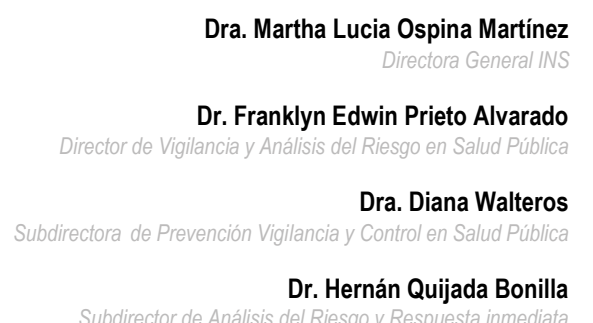

Una publicación del:

Instituto Nacional de Salud Dirección de Vigilancia y Análisis del Riesgo en Salud Pública Publicación en línea: ISSN 2357-6189 https://doi.org/10.33610/23576189.2021.22

Asistencia técnica de:

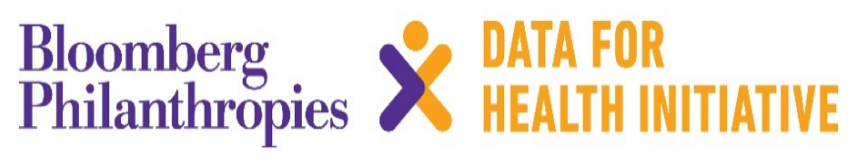

Situación Nacional

Grupo Sivigila sivigila@ins.gov.co

Mortalidad

Giana Maria Henriquez Mendoza ghenriquez@ins.gov.co

María Eugenia Pinilla Saraza mpinillas@ins.gov.co

Diana Alexa Forero Motta dforero@ins.gov.co

Eventos Trazadores

Andrea Jineth Rodriguez Reyes arodriguezr@ins.gov.co
Sandra Milena Aparicio Fuentes saparicio@ins.gov.co

Carolina Ferro Mendez cferro@ins.gov.co

Brotes

Gestor sistema de alerta temprana eri@ins gov.co

Gestor sistema de alerta temprana eri@ins gov.co
Angela Patricia Alarcón aalarcon@ins.gov.co

Tablas de mando

Yudy Silva Lizarazo ysilva@ins.gov.co

Diana Riveradrivera@ins.gov.co

Editor

Dr. Hernán Quijada Bonilla hquijada@ins.gov.co

Diseño y diagramación

Alexander Casas acasasc@ins.gov.co
La salud

es de todos 